\title{
LEAN SEIS SIGMA: UMA CONTRIBUIÇÃO BIBLIOMÉTRICA DOS ÚLTIMOS 15 ANOS
}

\section{LEAN SIX SIGMA: A BIBLIOMETRIC CONTRIBUTION OF THE LAST 15 YEARS}

\author{
Kellen Dayelle Endler* E-mail: kellen dayelle@hotmail.com \\ Luiz Eduardo Bourscheidt* E-mail: eng.luizeduardo@hotmail.com \\ Cassius Tadeu Scarpin* E-mail: cassiusts@gmail.com \\ Maria Teresinha Arns Steiner* E-mail: tere@ufpr.br \\ Paula Andrea da Rosa Garbuio** E-mail: paula.garbuio@pucpr.br \\ *Universidade Federal do Paraná, Curitiba, PR \\ **Pontifícia Universidade Católica do Paraná, Curitiba-PR
}

Resumo: A organização de dados sobre a produção científica de um período contribui para a continuidade das investigações e evolução de uma dada área do conhecimento. O objetivo principal desse estudo, portanto, é investigar o perfil das pesquisas sobre o Lean Seis Sigma (LSS), entre 1999 e 2014. O trabalho foi realizado apoiando-se em técnicas bibliométricas, por meio da consulta à base ISI Web of Knowledge e seu tratamento dos dados pelos softwares Sitkis ${ }^{\circledR}$ e Ucinet ${ }^{\circledR}$. Para a pesquisa utilizou-se "Lean Six Sigma" como expressão-chave, gerando uma amostra constituída por 84 artigos publicados. Ao final do estudo foram apresentados resultados de estatística descritiva com a identificação dos autores, artigos e periódicos mais referenciados por estudiosos em todo o mundo. Além das principais redes de relacionamento de autores e citações; nuvem de palavras-chave; e as abordagens metodológicas preferidas pelos autores. Este trabalho, então, torna-se um importante aliado no desenvolvimento de novas ideias, conceitos e perspectivas de abordagens sobre o LSS.

Palavras-chave: Manufatura Enxuta. Lean production. Seis Sigma.

Abstract: The organization of data on the scientific production of a period contributes to the continuity of research and development of a particular area of knowledge. The main objective of this study is, therefore, to investigate the profile of the research, the main themes, trends and gaps of scientific literature on Lean Six Sigma (LSS) between 1999 and 2014. The study was conducted relying on bibliometrics techniques, by consulting the ISI Web of Knowledge and its treatment of data by Sitkis ${ }^{\circledR}$ and Ucinet ${ }^{\circledR}$ software. For the research used "Lean Six Sigma" as an expression key, generating a sample of 84 published articles. At the end of the study were presented descriptive statistics results with the identification of the authors, articles and journals most referenced by scholars worldwide. Besides the main social networks of authors and citations; cloud keywords; and methodological approaches preferred by the authors. This work, then, becomes an important ally in the development of new ideas, concepts and perspectives of approaches to the LSS.

Keywords: Lean Manufacturing. Lean production. Six Sigma.

\section{INTRODUÇÃO}

Nos últimos 15 anos, observou-se um crescente interesse tanto por parte de empresas quanto dos acadêmicos em relação ao Lean Seis Sigma (LSS). Dentre as 
várias metodologias existentes de melhoria de processos, Seis Sigma e Lean permanecem como as melhores e mais amplamente utilizadas por várias empresas, sendo consideradas atualmente como estado da arte (SALAH, RAHIM e CARRETERO, 2010). A aplicação do LSS como uma abordagem integrada das duas metodologias, segundo os autores, tem gerado às empresas impacto positivo no desempenho do negócio.

É fato que tanto o Lean quanto o Seis Sigma, individualmente, têm sido objeto de estudo altamente explorado pelas comunidades acadêmicas nas últimas décadas. A divulgação de ganhos financeiros consideráveis alcançados por empresas do mundo todo juntamente com a expectativa de menor custo, melhor qualidade, mais velocidade do processo e bom uso do capital empregado (GEORGE, 2002), atrai muitos profissionais, entusiastas e inspiradores da metodologia. LSS trata-se de uma das áreas que vem apresentando cada vez mais evidência não somente a nível teórico de conferências e revistas especializadas, como na aplicação prática em empresas de produtos ou serviços.

O avanço científico nesse campo de estudo, portanto, deriva fundamentalmente do conhecimento disponível sobre ele, que é fruto de investigações e interações entre pesquisadores ao longo do tempo. Conhecer a evolução do LSS, os principais estudiosos e a produção acadêmica de maior relevância pode colaborar significativamente para a melhor compreensão da teoria existente e para a identificação de tendências, lacunas e problemas que ainda não foram solucionados.

A partir dessa perspectiva, o objetivo da pesquisa é analisar a produção científica sobre Lean Seis Sigma de maneira quantitativa. A abordagem metodológica utilizada tem por base a teoria bibliométrica e análise de redes. Dessa forma, busca-se investigar o perfil das pesquisas sobre o LSS, identificando-se, por exemplo, os principais autores e obras, bem como os temas mais relevantes tratados na área, tendências e lacunas.

Este artigo está estruturado em seis partes. Uma revisão bibliográfica que discute os principais conceitos encontra-se na seção 2. A descrição do método de seleção da amostra de artigos e as técnicas de análise são apresentadas na seção 3. $\mathrm{Na}$ seção 4, são apresentados os resultados encontrados e, por fim, a seção 5 compõem-se das considerações finais, das limitações deste trabalho e das sugestões para futuras pesquisas.

Revista Produção Online, Florianópolis, SC, v. 16, n. 2, p. 575-605, abr./jun. 2016. 


\section{INTEGRAÇÃO ENTRE LEAN E SEIS SIGMA}

O Lean Manufacturing é uma filosofia de gestão que surgiu no Japão, na Toyota Motors Company, após a segunda Guerra Mundial, como resultado da necessidade de sobrevivência no mercado automobilístico japonês (MERCADO, 2014). Forçado pela escassez de capital e recursos, Eiji Toyoda instruiu seus trabalhadores para eliminar todos os desperdícios. Sendo que desperdício foi definido como qualquer coisa que não seja a quantidade mínima de equipamentos, materiais, peças, espaço e tempo que são absolutamente essenciais para agregar valor ao produto (RUSSELL e TAYLOR, 2000). Assim, o executivo Taichi Ohno e associados iniciaram a criação de um sistema de produção de caráter alternativo, denominado Toyota Production System (STP - Sistema Toyota da Produção).

O STP, por representar uma forma de produzir cada vez mais com cada vez menos, foi denominado por KRAFCIK (1988) de Produção Enxuta. Termo esse, popularizado pela obra de Womack, Jones e Roos (1990). Em 1997, Womack e Jones publicam o trabalho intitulado por "Lean Thinking" - dois anos mais tarde traduzido e publicado no Brasil como "A Mentalidade Enxuta nas Empresas". O Lean Thinking ampliava as ideias, conceitos e práticas da Toyota, tornando-se efetivamente uma filosofia e uma cultura empresarial, que poderia ser disseminada para empresas dos mais diferentes tipos e setores (WOMACK e JONES, 1997). Assim, pelo fato do Lean Manufacturing (ou Lean Production) poder ser aplicado em diferentes segmentos, uma denominação mais apropriada segundo Werkema (2011a) é Lean Enterprise ou Lean Operations. Arnheiter e Maleyeff (2005) usam o termo Lean Management. Enquanto no presente trabalho, utiliza-se simplesmente Lean.

A metodologia Seis Sigma, por sua vez, é uma estratégia gerencial disciplinada e altamente quantitativa, que visa aumentar expressivamente a performance e a lucratividade das empresas, por meio da melhoria da qualidade de produtos e processos e do aumento da satisfação de clientes e consumidores (WERKEMA, 2011b). É uma iniciativa que busca criar processos de manufatura, serviço ou administrativo que gerem no máximo 3,4 problemas por milhão de oportunidades (MORO e PÁDUA, 2008).

O Seis Sigma nasceu na Motorola, em 1987, criado a partir de conceitos e métodos propostos por Bill Smith. O objetivo do programa era fabricar produtos de Revista Produção Online, Florianópolis, SC, v. 16, n. 2, p. 575-605, abr./jun. 2016. 
qualidade superior a preços menores que seus concorrentes. Mais detalhes podem ser encontrados em Smith (2003). Assim que o Seis Sigma foi criado na Motorola criou-se uma série de passos para alcançar o nível Seis Sigma, que mais tarde foram substituídos por quatro fases (Medir, Analisar, Melhorar e Controlar) pela General Electric (GE). Depois disso, a fase Definir foi adicionada antes da fase Medir para formar o método DMAIC (Define, Measure, Analyse, Improve, Control). O DMAIC é um método estruturado para melhoria do desempenho de produtos e processos. Para o desenvolvimento de novos produtos e processos, utiliza-se o método DMADV (Define, Measure, Analyse, Design, Verify) cujas fases são: Definir, Medir, Analisar, Projetar e Verificar, ou o DFSS (Design for Six Sigma).

O termo Lean Seis Sigma (LSS) é usado para descrever a integração de duas áreas de melhoria operacional anteriormente separadas, o Lean e o Seis Sigma (SHERIDAN, 2000; ARNHEITER e MALEYEFF, 2005; GEORGE, 2002; MADER, 2008; JING, 2009). Werkema (2012) afirma que a integração das duas metodologias é natural, de modo que a empresa usufrui dos pontos fortes de ambas estratégias. 0 Lean Manufacturing não conta com um método estruturado e profundo de solução de problemas e com ferramentas estatísticas para lidar com a variabilidade, da mesma forma que o Seis Sigma não enfatiza a melhoria da velocidade dos processos e a redução do lead time, complementando-se um ao outro, como exemplifica a autora.

O LSS é descrito como uma metodologia de melhoria contínua (SNEE, 2010; SALAH, RAHIM e CARRETERO, 2010) que visa reduzir desperdícios, aumentar o desempenho do processo, resultando em maior satisfação de clientes e acionistas. Também pode ser visto como uma estratégia de negócios (ALBLIWI et al., 2014; WERKEMA, 2012), no sentido de que todas as pessoas da empresa, nos diferentes níveis de aprofundamento do programa, são responsáveis por conhecer e implementar seus conceitos e metodologia.

\subsection{Relatos de Sucesso com a Integração}

A primeira integração de Lean e Seis Sigma ocorreu em 1986, no grupo de George com sede nos EUA (SALAH, RAHIM e CARRETERO, 2010). No entanto, o termo LSS foi introduzido pela primeira vez na literatura por volta de 2000 (ANTONY et al., 2012; LAUREANI e ANTONY, 2012; SNEE, 2010). Também foi denominado 
pelos termos: Lean Sigma (SHERIDAN, 2000); Seis Sigma Lean (BYRNE, LUBOWE e BLITZ, 2007) além de Seis Sigma Plus pela multinacional estadunidense Honeywell (KOVACH et al., 2005).

Além do sucesso do LSS em empresas líderes como a General Eletric e a Toyota, outras empresas obtiveram êxito com o programa, tais como: Motorola, Honeywell, Du Pont, Merck, Johnson \& Johnson, Bank of America e outras (KUMAR et al., 2006; LEIPOLD, 2007; SHAH, CHANDRASEKARAN e LINDERMAN, 2008; LAUREANI e ANTONY, 2012; SNEE, 2010); além de algumas empresas de pequeno e médio porte (ANTONY et al., 2005; KUMAR ANTONY e TIWARI, 2011). A alegação de que Lean e Seis Sigma tem uma relação de complementaridade é hoje, amplamente aceita e cada vez mais empresas estão estabelecendo programas de LSS ((SALAH, RAHIM e CARRETERO, 2010); (PINHEIRO, SCHELLER e MIGUEL, 2013)).

Embora sejam muitas e notáveis as histórias de sucesso de implantação LSS no mundo industrial, muitos trabalhos acadêmicos apontam que nem todas as organizações obtém benefícios reais da implementação do LSS; uma tentativa mal sucedida de implementação do LSS pode realmente torná-la ineficaz (CHAKRAVORTY, 2009; GLASGOW et al., 2010; KUMAR et al., 2008; ALBLIWI et al., 2014). Alguns relatos de insucessos com a implantação do LSS são apresentados a seguir.

\subsection{Relatos de Insucesso com a Integração}

A integração de Lean Seis Sigma não é percebida por todos como uma união eficaz. Há algumas críticas na literatura sobre a combinação das duas abordagens. Talvez o autor mais crítico seja Bendell (2006), que tem vasta experiência tanto profissional quanto acadêmica neste campo. Ele argumenta que Lean e Seis Sigma se tornaram "filosofias mal definidas". Afirma que as metodologias são alocadas sem explicação lógica e, mais importante, sem nenhuma base teórica ou explicação para a escolha das técnicas. No entanto, Bendell sugere que seria benéfico para todos, se existisse uma abordagem única que efetivamente vinculasse as duas filosofias.

Outrossim, Mika (2006) assume a posição de que as duas abordagens são completamente incompatíveis uma com o outra, afinal, o Seis Sigma não pode ser adotado pelo "trabalhador do chão de fábrica". Ele argumenta que o Lean, por sua 
vez, tem por característica ser acessível a estes trabalhadores, incentivando 0 trabalho em equipe eficaz por meio da colaboração e participação de equipes multifuncionais.

Vários autores têm constatado que, embora as empresas tenham implantado com sucesso iniciativas de melhoria contínua como Lean e Seis Sigma, um número significativo de empresas falham em atingir os resultados esperados (KUMAR et al., 2008; MARTINEZ-JURADO e MOYANO-FUENTES, 2012; ALBLIWI et al., 2014). Segundo Ringen e Holtskog (2011), de cada três projetos de melhoria contínua em geral, dois não conseguem atingir os resultados esperados.

Em relação a implantação do Lean em empresas, uma pesquisa realizada em organizações do Reino Unido, mostrou que menos de 10\% das organizações tiveram sucesso (BHASIN E BURCHER, 2006). Enquanto que Pedersen e Huniche (2011) reportam que no setor público Dinamarquês até $70 \%$ das empresas que aplicaram Lean falharam. Uma revisão de 47 estudos na área da saúde empreendida por Glasgow et al. (2010) concluiu que $62 \%$ de iniciativas do Lean e Seis Sigma falharam.

Essas falhas e insatisfação com os resultados ocorrem devido à falta de atenção por parte das empresas para com os fatores críticos de sucesso durante a implementação, citados na seção 2.3.

\subsection{Fatores críticos de sucesso para o LSS}

Alguns autores sugeriram fatores críticos de sucesso para a implantação do LSS, como o comprometimento e envolvimento da alta direção, a comunicação efetiva com os trabalhadores do chão de fábrica e a seleção adequada de projetos, por exemplo. A desconsideração desses fatores implica em falhas de muitos projetos de melhoria contínua ((CHAKRAVORTY, 2009), (LAUREANI; ANTONY, 2012); (SNEE, 2010); (MARZAGÃO et al., 2014)).

Antony (2006) indica que o compromisso da alta direção da GE foi fundamental para o sucesso da implantação do Seis Sigma. Martin (2007) indicou que alguns principais fatores de sucesso do LSS incluem escolher as pessoas certas, os projetos certos e estabelecer uma comunicação eficaz. O sucesso e o fracasso da implementação do LSS dependem, além disso, de como e onde é aplicado (DUARTE et al., 2012). 
Manville et al. (2012) destacam a importância do desenvolvimento da capacidade de aprendizagem da equipe e de sua capacitação. Albliwi et al. (2014), por sua vez, exploram os fatores críticos de insucesso do LSS em diferentes setores - tais como manufatura, serviços e ensino superior - identificando 34 fatores comuns ao LSS, como a falta de comprometimento da alta direção, a falta de comunicação, falta de formação das equipes e recursos limitados.

\section{METODOLOGIA}

A bibliometria é definida como a técnica de investigação que tem por fim a análise do tamanho, crescimento e distribuição da bibliografia num determinado campo do conhecimento (PILKINGTON; MEREDITH, 2009). Essa ferramenta de análise quantitativa da literatura foi introduzida por Pitchard (1969) (SUN; WANG; HO, 2012). A análise bibliométrica tem amplas aplicações em diversas áreas com o intuito de aumentar o desempenho de pesquisas ou avaliar suas tendências, investigando as características das publicações, tais como: autoria, fontes de pesquisa, temas, origens geográficas, citações e cocitações (SMALL, 2003).

Para a condução desse estudo bibliométrico, retomam-se os objetivos descritos na introdução, que derivam do problema de pesquisa que orienta toda a investigação: Qual o perfil das pesquisas, os principais temas tratados, as tendências e lacunas da produção científica sobre o Lean Seis Sigma?

Para responder essa pergunta, estabeleceram-se três etapas, ilustradas na Figura 1.

Figura 1 - Processo de Pesquisa

$\left.\left.\Xi \begin{array}{l}\text { Definição da amostra na } \\ \text { base de dados do ISI Web of } \\ \text { Knowledge (Seção 3.1); }\end{array}\right] \begin{array}{ll}\text { Organização e tratamento } \\ \text { bibliométrico dos registros } \\ \text { coletados (Seção 3.2); }\end{array}\right] \begin{aligned} & \text { Análise e interpretação dos } \\ & \text { resultados encontrados } \\ & \text { (Seção 4). }\end{aligned}$

Fonte: Os autores

\subsection{Definição da Amostra}

A amostra de artigos sobre LSS foi definida a partir da escolha da base de dados, da identificação das palavras-chave e da determinação dos tipos de documentos publicados, conforme ilustrado no fluxograma da Figura 2. 
Figura 2 - Fluxograma do processo de definição da amostra (referente a fevereiro de 2015)

\begin{tabular}{|c|c|c|c|}
\hline 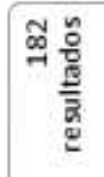 & $\begin{array}{l}\text { Pesquisa Coleção do ISI Web of Science: } \\
\text { Expressões-chave } \\
\text { ("Lean Six Sigma") }\end{array}$ & 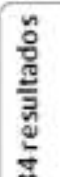 & $\begin{array}{l}\text { Tipos de documentos } \\
\text { (ARTICLES) }\end{array}$ \\
\hline
\end{tabular}

Fonte: Os autores

Quanto à determinação da base de dados, optou-se por utilizar a plataforma ISI Web of Knowledge, por incluir revistas com fator de impacto calculado no JCR (Journal Citation Report), além de fornecer um conjunto relevante de informações para a análise bibliométrica (CARVALHO, FLEURY e LOPES, 2013). O tratamento dos dados seguiu utilizando-se a expressão "Lean Six Sigma". Vale ressaltar que descartou-se a expressão "Lean Seis Sigma" por não contribuir no número de artigos da amostra. Resultaram do esforço descrito 182 artigos.

Quanto à determinação do tipo de publicação - livros, patentes, artigos, anais de congressos, etc. - optou-se por considerar apenas artigos. Entende-se que a escolha é válida, pois artigos acadêmicos geralmente antecedem livros consagrados, são considerados fontes seguras para pesquisas e devem apresentar rigor metodológico para publicação. A composição da amostra, então, foi concluída com artigos de 1999 a 2014, sem que se impusesse restrições quanto aos anos de publicação. A pesquisa retornara um total de 84 artigos a serem analisados, todos do idioma inglês.

Para a análise das abordagens metodológicas sobre o LSS, fez-se a leitura dos resumos e/ou dos artigos integralmente. Dos 84 artigos da amostra, os seguintes quatro artigos não disponibilizavam informações suficientes para que as análises pudessem ser feitas de forma adequada: Kandebo (1999), Caldwell (2005), Breyfogle (2009) e Reutter e Wassenhoven (2009). Assim, estes artigos foram excluídos, restando um total de 80 artigos analisados.

\subsection{Organização e tratamento bibliométrico dos registros coletados}

O tratamento bibliométrico dos registros coletados é apresentado por meio da estatística descritiva, obtida por meio de tabelas e gráficos ilustrativos gerados através do software Microsoft Excel ${ }^{\circledR}$. Os 84 artigos da amostra foram, primeiramente, distribuídos por ano; por autores; país de origem; periódicos e 
número de citações. Adicionalmente, foi utilizada a ferramenta Wordle ${ }^{\mathrm{TM}}$ para a construção das nuvens de palavras, conceito que será oportunamente definido no decorrer deste artigo. Além dessas, informações sobre características de autoria estão descritas na seção 4.1 .

Em seguida, para estabelecimento das bases teóricas, elaborou-se redes sociais de citação e cocitação dos artigos da amostra e suas referências (seção 4.2). Para tanto, recorreu-se à ferramenta SITKIS ${ }^{\circledR}$ (SCHILDT, 2002) para relacionar os dados de saída do banco de dados ISI Web of Knowledge (Web of Science), ao programa UCINET ${ }^{\circledR}$ para codificar os relacionamentos e ao NetDraw ${ }^{\circledR}$ (BORGATTI; EVERETT; FREEMAN, 2002) para ilustrar os diagramas de relacionamento.

Em relação às abordagens metodológicas preferidas pelos autores (seção 4.3), utiliza-se inicialmente, o modelo utilizado por Croom, Romano e Giannakis (2000), que classifica as pesquisas como descritivo ou prescritivo e com base empírica ou conceitual. Segundo os autores, as duas divisões epistemológicas referem-se à:

- Caracterização da literatura: estudos teóricos são aqueles que dedicamse a analisar os fenômenos de causa e efeito e propõem conceitos/modelos analíticos, enquanto que estudos empíricos concentram-se em informações práticas. Estudos tanto teóricos quanto empíricos podem ser considerados como aqueles que desenvolvem hipóteses e as testam empiricamente; e

- Contribuição do estudo: que classifica os estudos em descritivos e/ou prescritivos. Estudos descritivos objetivam explanar e sumarizar práticas atuais e, por outro lado, os estudos prescritivos propõem práticas a serem adotadas pelas empresas.

As pesquisas também foram classificadas em relação aos objetivos, à abordagem do problema e aos procedimentos (seção 4.3). Quanto aos objetivos, as pesquisas foram classificadas em: Exploratória, Descritiva e Explicativa. Quanto à abordagem, em Qualitativa e Quantitativa. E em relação aos procedimentos, as pesquisas foram divididas em Pesquisa Bibliográfica ou Documental; Levantamento (Survey), Estudo de Caso (Simples e Múltiplos) e Pesquisa-Ação.

Para explorar tendências do tema para o futuro e reforçar interfaces com outras áreas, identificam-se as principais temáticas dos trabalhos da amostra 
publicados sobre o LSS, cujos resultados apresentam-se na seção 4.4 e apresentase alguns possíveis tópicos direcionadores de estudos dentro do LSS (seção 4.5).

\section{ANÁLISE DOS RESULTADOS}

\subsection{Análise das publicações}

Uma primeira análise descritiva das publicações procurou identificar tendências de crescimento ou declinação no interesse de desenvolvimento de estudos na área do LSS, classificando os artigos da amostra de acordo com o ano de publicação (Figura 4). Observou-se que o desenvolvimento de trabalhos sobre LSS é bastante recente, sendo 1999 o ano de sua primeira publicação.

Figura 3 - Evolução das publicações da amostra ao longo do tempo

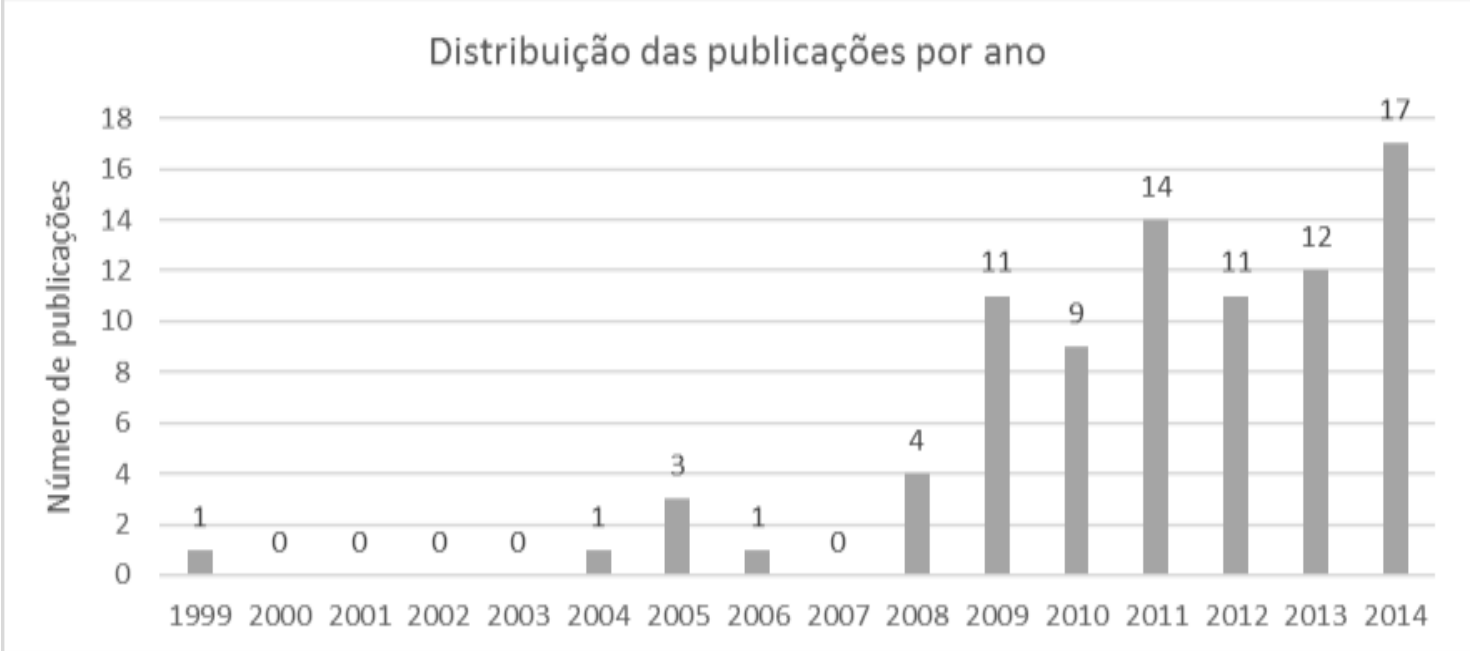

Fonte: Os autores

Ressalta-se a ocorrência de poucos estudos de 1999 até 2008. No entanto, um trabalho dessa época teve forte influência no fomento de novas pesquisas sobre o tema. Trata-se do estudo de Furterer e Elshennawy (2005), que é um dos primeiros artigos a tratar do TQM e LSS em entidades públicas. Afinal, trabalhos relacionados a essas abordagens, em sua maioria vinham sendo implantados em indústrias privadas, com foco principalmente em aplicações na manufatura. Este artigo apresenta um estudo de caso aplicando ferramentas e princípios LSS na melhoria da qualidade e oportunidade de fornecer serviços governamentais locais.

A partir de 2008 houve uma evidente aceleração de publicações sobre o tema, o que permite inferir que o LSS vem sendo alvo de um crescente interesse por Revista Produção Online, Florianópolis, SC, v. 16, n. 2, p. 575-605, abr./jun. 2016. 
parte da comunidade acadêmica. O ano de 2014 apresentou o maior volume de publicações com 17 artigos no total.

Uma segunda análise descritiva procurou avaliar a dispersão dos trabalhos, a fim de identificar os principais autores e periódicos em volume de publicações, conforme indicado nas Figura 4 e Figura 5.

A análise dos autores que mais publicam sobre o tema, revela, primeiramente, a falta de maturidade da temática LSS. Afinal, áreas mais maduras tendem a ter pesquisadores com histórico de pesquisa relevante (NEDERHOF, 2006). E o que se pode observar é que esta distribuição apresenta uma dispersão considerável.

Os autores com maior número de trabalhos são representados por um grupo constituído de 24 autores, com número de publicações na amostra acima de dois artigos. Um autor se destaca nessa análise: Jiju Antony, da Heriot-Watt University, universidade de Edimburgo, Escócia. Esse autor estuda a aplicação do LSS em hospitais (GIJO, ANTONY, 2014) e em pequenas e médias empresas (MCADAM et al., 2014; TIMANS et al., 2012).

Figura 4 - Autores com maior número de publicações da amostra

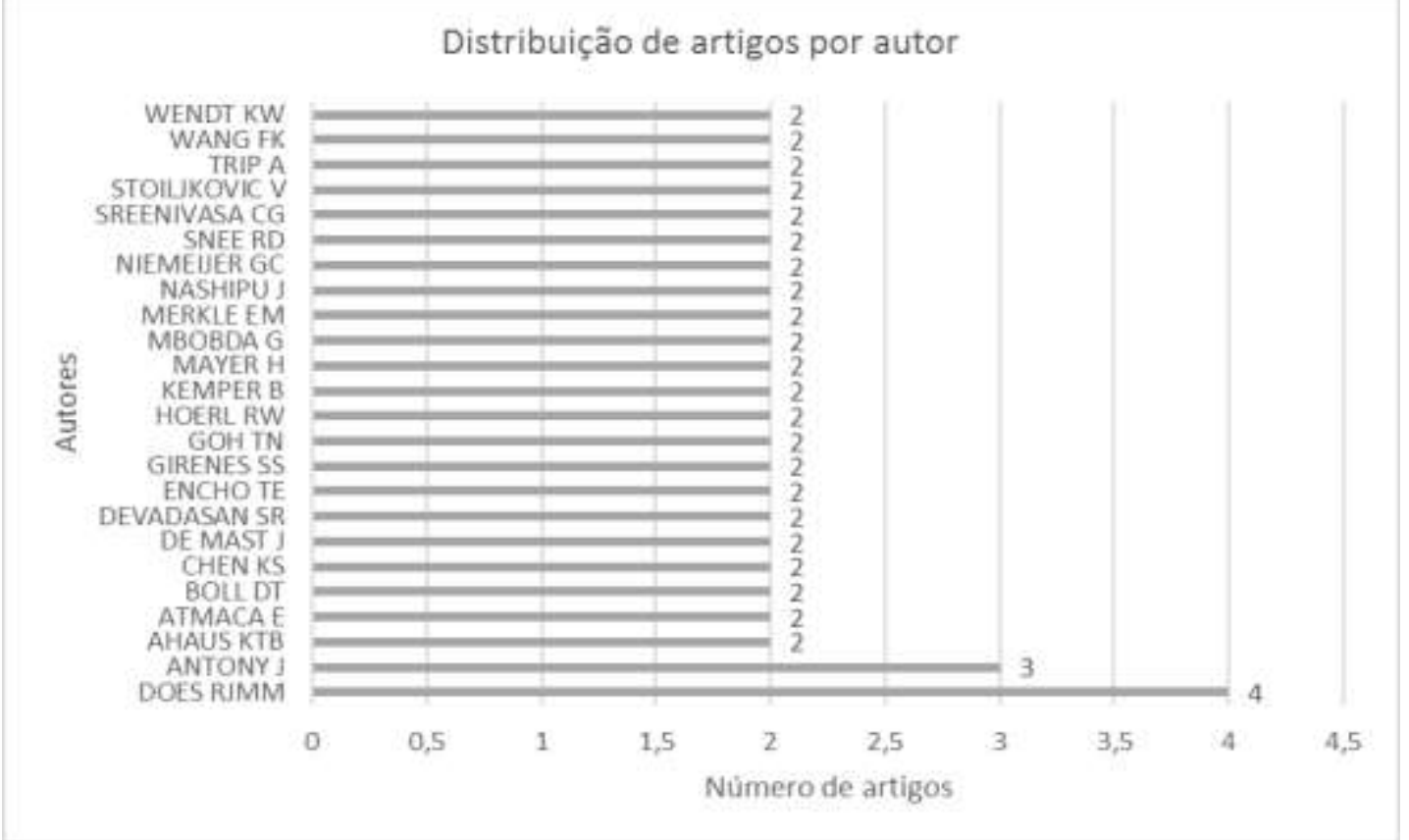

Fonte: Os autores

Outro ponto interessante refere-se a características de autoria quanto ao número de autores que publicam cada artigo. Os artigos de autoria individual, compõem apenas $19 \%$ da amostra, ou seja, ocorrem em menor número em Revista Produção Online, Florianópolis, SC, v. 16, n. 2, p. 575-605, abr./jun. 2016. 
comparação a soma de artigos com 2 autores (correspondente a 30\%) ou 3 ou mais autores, que compõe $51 \%$ do total de artigos da amostra. Tal fato pode ser indicativo da existência de grupos de pesquisa sobre a temática. A colaboração entre autores vem sendo vista internacionalmente como um dos indicadores de qualidade da pesquisa, principalmente em temas multidisciplinares (SUBRAMANYAM, 1983), como é o caso do LSS.

Com o intuito de expor os principais núcleos de pesquisa aos quais os autores estão filiados aprofunda-se um pouco mais a investigação. Existe um predomínio acentuado de publicações originárias dos Estados Unidos (34 artigos), seguido da Holanda, Índia, Taiwan e Alemanha, com número de publicações de 9, 7, 6 e 5 artigos, respectivamente. As universidades que despontam como centros de pesquisas sobre o tema são a Universidade de Amsterdam (com cinco artigos) e Universidade de Groningen (três artigos), ambas da Holanda, seguida da Universidade de Strathclyde do Reino Unido (três artigos).

É importante mencionar que o Brasil possui apenas uma única publicação. Este trabalho tem o título: "Lean, Six Sigma and Lean Six Sigma: an analysis based on operations strategy". Foi publicado na International Journal of Production Research. Drohomeretski et al. (2014) analisaram indústrias situadas no Sul do Brasil, que utilizavam o Lean, Seis Sigma ou o LSS. Para cada um desses três modelos de gestão, analisaram as diferenças e complementaridades nas áreas de decisão de produção e identificaram prioridades competitivas que levavam as organizações a um melhor desempenho.

Com relação à distribuição dos artigos da amostra por periódicos de publicação, nota-se que não há um conjunto de periódicos com destaque significativo em volume de publicações, o que pode ser atribuído ao caráter multidisciplinar do tema. Observa-se na Figura 5 que, o periódico com maior destaque em volume de publicações é o Total Quality Management Business Excellence, seguido do Quality and Reliability Engineering International, Quality Engineering e Production Planning Control. Os dez principais periódicos citados na Figura 5, são responsáveis por 32 publicações sobre o tema, o que representa aproximadamente $38 \%$ da amostra.

Os artigos com os maiores números de citações da amostra são apresentados no Tabela 1. Também apresenta-se o fator de impacto de cada 
periódico, apurado pelo JCR, recurso que permite avaliar e comparar a os periódicos e sua relevância em uma determinada área.

Figura 5 - Comparativo da distribuição das publicações da amostra pelos principais periódicos

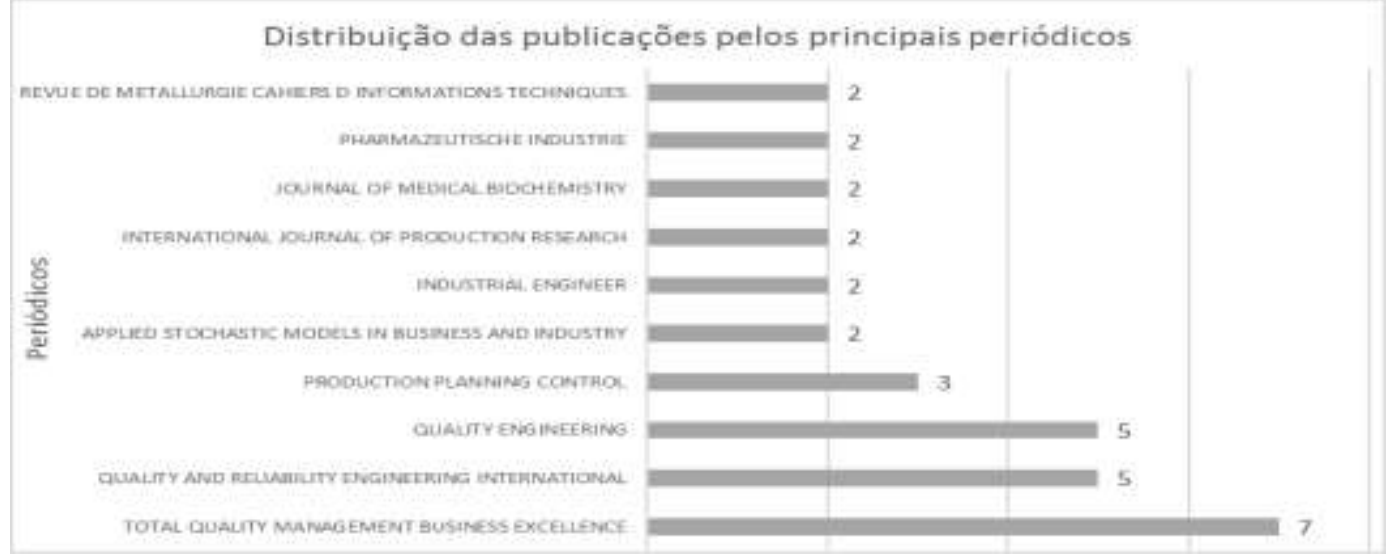

Fonte: Os autores

Tabela 1 - As primeiras 15 publicações mais citadas da amostra

\begin{tabular}{|c|c|c|c|c|c|}
\hline Autores & Título da fonte & 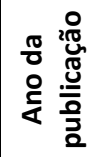 & 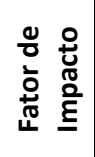 & 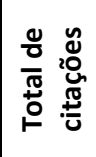 & 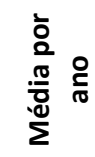 \\
\hline Shah, R.; Chandrasekaran, A.; Linderman, K. & $\begin{array}{l}\text { INTERNATIONAL JOURNAL OF } \\
\text { PRODUCTION RESEARCH }\end{array}$ & 2008 & 1,323 & 28 & 3.50 \\
\hline Furterer, S; Elshennawy, AK & $\begin{array}{l}\text { TOTAL QUALITY MANAGEMENT } \\
\& \text { BUSINESS EXCELLENCE }\end{array}$ & 2005 & 0,59 & 27 & 2.45 \\
\hline Hoerl, Roger W.; Snee, Ron & QUALITY ENGINEERING & 2010 & 0,355 & 17 & 2.83 \\
\hline $\begin{array}{l}\text { Niemeijer, Gerard C.; Trip, Albert; Ahaus, Kees T. B.; } \\
\text { Does, Ronald J. M. M.; Wendt, Klaus W. }\end{array}$ & $\begin{array}{l}\text { JOURNAL OF TRAUMA-INJURY } \\
\text { INFECTION AND CRITICAL CARE }\end{array}$ & 2010 & 2,961 & 16 & 2.67 \\
\hline Chen, MingNan; Lyu, JrJung & $\begin{array}{l}\text { PRODUCTION PLANNING \& } \\
\text { CONTROL }\end{array}$ & 2009 & 0,991 & 9 & 1.29 \\
\hline Chassin, Robert & $\begin{array}{l}\text { MOUNT SINAI JOURNAL OF } \\
\text { MEDICINE }\end{array}$ & 2008 & 1,563 & 9 & 1.12 \\
\hline Maguad, BA & $\begin{array}{l}\text { TOTAL QUALITY MANAGEMENT } \\
\text { \& BUSINESS EXCELLENCE } \\
\end{array}$ & 2006 & 0,59 & 8 & 0.80 \\
\hline Wang, Fu-Kwun; Chen, Kao-Shan & $\begin{array}{l}\text { TOTAL QUALITY MANAGEMENT } \\
\text { \& BUSINESS EXCELLENCE } \\
\end{array}$ & 2010 & 0,59 & 7 & 1.17 \\
\hline $\begin{array}{l}\text { Does, Ronald J. M. M.; Vermaat, Thijs M. B.; Verver, } \\
\text { John P. S.; Bisgaard, Soren; Van den Heuvel, Jaap }\end{array}$ & $\begin{array}{l}\text { JOURNAL OF QUALITY } \\
\text { TECHNOLOGY } \\
\end{array}$ & 2009 & 1,271 & 7 & 1.00 \\
\hline Goh, T. N. & $\begin{array}{l}\text { QUALITY AND RELIABILITY } \\
\text { ENGINEERING INTERNATIONAL }\end{array}$ & 2011 & 0,994 & 6 & 1.20 \\
\hline $\begin{array}{l}\text { Aakre, Kenneth T.; Valley, Timothy B.; O'Connor, } \\
\text { Michael K. }\end{array}$ & RADIOGRAPHICS & 2010 & 2,729 & 6 & 1.00 \\
\hline Sugiyama, Hirokazu; Sukowski, Lars; Schmidt, Rainer & PHARMAZEUTISCHE INDUSTRIE & 2011 & 0,194 & 5 & 1.00 \\
\hline Cheng, Chen-Yang; Chang, Pu-Yuan & $\begin{array}{l}\text { TOTAL QUALITY MANAGEMENT } \\
\text { \& BUSINESS EXCELLENCE } \\
\end{array}$ & 2012 & 0,59 & 4 & 1.00 \\
\hline $\begin{array}{l}\text { de Mast, Jeroen; Kemper, Benjamin; Does, Ronald J. M. } \\
\text { M.; Mandjes, Michel; van der Bijl, Yohan }\end{array}$ & $\begin{array}{l}\text { QUALITY AND RELIABILITY } \\
\text { ENGINEERING INTERNATIONAL } \\
\end{array}$ & 2011 & 0,994 & 4 & 0.80 \\
\hline $\begin{array}{l}\text { Roth, Christopher J.; Boll, Daniel T.; Wall, Lisa K.; } \\
\text { Merkle, Elmar M. }\end{array}$ & $\begin{array}{l}\text { AMERICAN JOURNAL OF } \\
\text { ROENTGENOLOGY }\end{array}$ & 2010 & 2,744 & 4 & 0.67 \\
\hline
\end{tabular}

Fonte: Os autores

Revista Produção Online, Florianópolis, SC, v. 16, n. 2, p. 575-605, abr./jun. 2016. 
O artigo de maior notoriedade pelo elevado número de citações é o de Shah; Chandrasekaran e Linderman (2008) com 28 citações, com média de 3,5 citações por ano. Trata-se de um estudo importante a nível teórico conceitual, por investigar padrões de implementação de práticas do Lean e Seis Sigma em 2.511 instalações.

Um ponto muito interessante é que este artigo mais citado é pertencente ao periódico International Journal of Production Research (IJPR), que caracteriza-se por uma revista altamente bem-sucedida de pesquisas sobre produção e manufatura. Enquanto que os periódicos mais relevantes são notoriamente de Gestão da Qualidade. Tal fato pode ser atribuído, primeiramente à própria origem do LSS como uma metodologia de melhoria de eficiência produtiva entrelaçada à melhoria de qualidade, de forma a criar operações fabris mais enxutas por intermédio do Lean e melhorar a qualidade para menos de 3,4 defeitos por milhão de eventos por meio do Seis Sigma.

Como última etapa da análise das publicações, estabelece-se uma nuvem de texto com as palavras-chave dos artigos da amostra, representadas na Figura 6. A nuvem de texto, ou nuvem de palavras, é uma forma de visualização de dados linguísticos que mostra a frequência com que as palavras aparecem em determinado contexto (LUNARDI, CASTRO, MONAT, 2008). Considerando a frequência de palavras-chave isoladas, termos mais tradicionais referentes ao LSS sobrepõem-se. A fim de proporcionar uma visão mais nítida das palavras, o critério de corte consistiu em analisar as 25 palavras-chave mais frequentes.

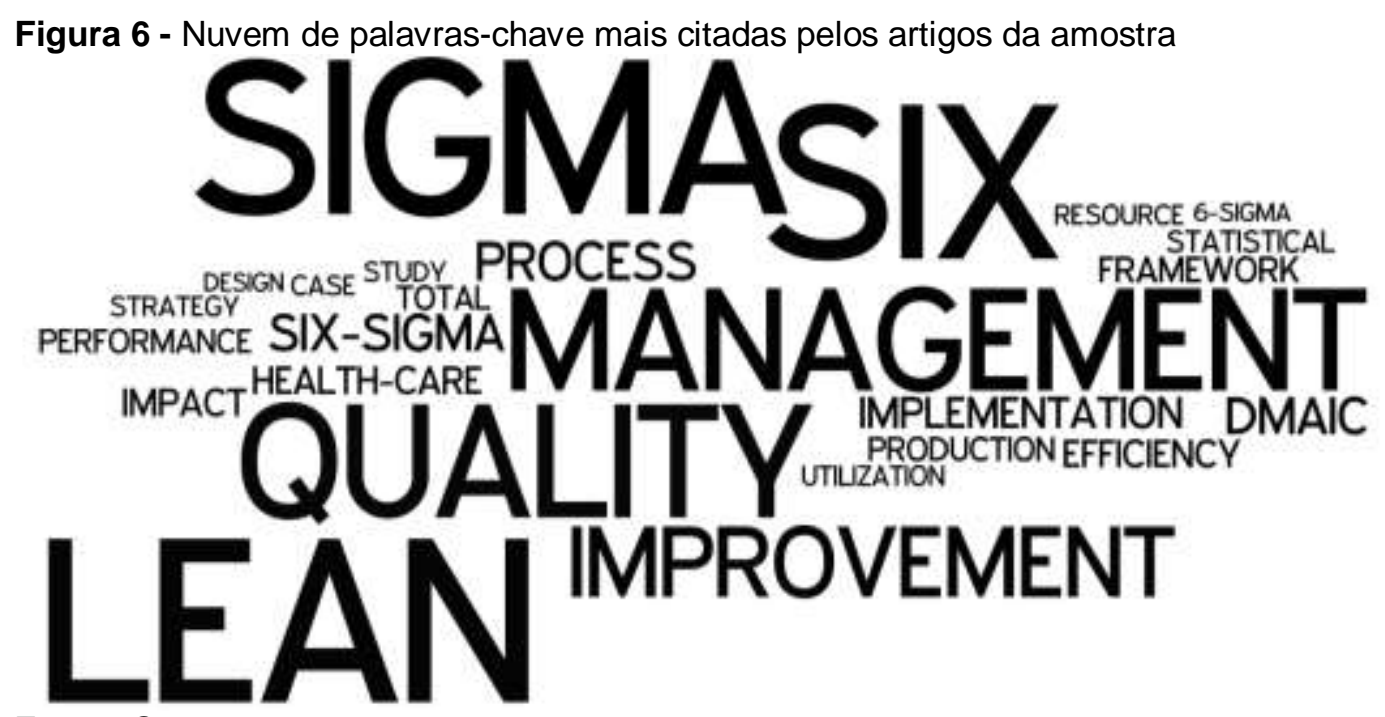

Fonte: Os autores 
Por exemplo, evidenciou-se palavras como "Management", "Quality", referindo-se principalmente ao "Total Quality Management" ou Gestão da Qualidade Total, movimento antecedente ao Seis Sigma. Outro destaque é o "DMAIC", o que induz a associação do mesmo como o principal método de desenvolvimento de projetos LSS.

O LSS tem transcendido suas origens do ambiente produtivo, para ser encontrado em praticamente todos os setores da indústria, e principalmente, nos últimos anos, em setores de serviços, incluindo cuidados de saúde e governamentais (MARSH; PERERA, 2011). Essa análise contribuiu para uma identificação clara do inter-relacionamento das principais temáticas sobre o LSS.

Uma palavra-chave importante é "Health-Care". Analisando-se as áreas de pesquisa das publicações, contata-se que aproximadamente $72 \%$ são pertencentes a áreas relacionadas à Saúde. Zhang (2012) também faz essa constatação observando que o LSS é implementado principalmente no setor da saúde, no qual segundo o autor "os defeitos são menos toleráveis". A Tabela 2 a seguir evidencia algumas pesquisas da amostra relacionadas à essa temática. 
Tabela 2 - Publicações da amostra relacionadas à temática da Saúde

\begin{tabular}{|c|c|c|c|}
\hline 운 & Artigo & Descrição & $\begin{array}{l}\text { Número } \\
\text { de } \\
\text { Citação }\end{array}$ \\
\hline 을 & $\begin{array}{l}\text { Niemeijer, Gerard } \\
\text { C.; Trip, Albert; } \\
\text { Ahaus, Kees T. B.; } \\
\text { et al. (2010) }\end{array}$ & $\begin{array}{l}\text { Trata da aplicação método Lean Seis Sigma para reduzir tempo de internação } \\
\text { hospitalar, no Centro Médico da Universidade Groningen nos Países Baixos. } \\
\text { Constatou-se que } 30 \% \text { do tempo médio de permanência era desnecessário, } \\
\text { devido a atrasos em diversas áreas. Com a implementação do LSS obteve-se } \\
\text { uma redução do redução do tempo médio de permanência dos pacientes de } 10,4 \\
\text { dias para 8,5 dias. }\end{array}$ & 21 \\
\hline $\bar{\sim}$ & $\begin{array}{l}\text { Yeh, Hseng-Long; } \\
\text { Lin, Chin-Sen; Su, } \\
\text { Chao-Ton; et al. } \\
\text { (2011) }\end{array}$ & $\begin{array}{l}\text { Este estudo aplica o método do LSS para melhorar o processo médico de infarto } \\
\text { agudo no miocárdio. Como resultados, o tempo de ciclo do processo diminuiu } \\
58,4 \% \text {. A eficiência do ciclo do processo aumentou } 32,27 \text { para } 51,81 \% \text {, e a média } \\
\text { de dias de permanência hospitalar diminuiu } 3 \text { dias. Os resultados do estudo } \\
\text { indicam que LSS não só melhorou a qualidade médica, mas também reforçou a } \\
\text { competitividade do mercado. }\end{array}$ & 3 \\
\hline$\frac{N}{\infty}$ & $\begin{array}{l}\text { van Lent, Wineke } \\
\text { A. M.; Sanders, E. } \\
\text { Marloes; van } \\
\text { Harten, Wim H. } \\
\text { (2012) }\end{array}$ & $\begin{array}{l}\text { Este estudo analisa as abordagens e ferramentas utilizadas para melhorar a } \\
\text { logística de pacientes em hospitais holandeses. Realizou-se um survey entre } \\
\text { especialistas em logística de pacientes em } 94 \text { hospitais holandeses e obteve-se } \\
48 \% \text { de hospitais participantes. } 98 \% \text { deles relataram ter usado várias abordagens } \\
\text { e } 39 \% \text { utilizaram cinco ou mais abordagens. Cerca de } 50 \% \text { dos hospitais que } \\
\text { avaliaram os efeitos de abordagens quanto a eficiência, tempos de produção e } \\
\text { resultados financeiros, relatando que haviam alcançado seus objetivos. }\end{array}$ & 3 \\
\hline \multirow{2}{*}{$\frac{m}{2}$} & $\begin{array}{l}\text { Niemeijer, Gerard } \\
\text { C.; Flikweert, } \\
\text { Elvira; Trip, Albert; } \\
\text { et al. (2013) }\end{array}$ & $\begin{array}{l}\text { Esse estudo teve por objetivo mostrar a aplicação do LSS para melhorar a } \\
\text { eficiência do atendimento em uma clínica de fraturas de quadril em idosos. } \\
\text { Resultados significativos foram alcançados através da redução tanto da média } \\
\text { do tempo de internação prolongado de } 4,2 \text { dias }(-31 \%) \text { e da duração média da } \\
\text { cirurgia por } 57 \text { minutos }(-36 \%) \text {. }\end{array}$ & 3 \\
\hline & $\begin{array}{l}\text { Chassin, Mark R. } \\
\text { (2013) }\end{array}$ & $\begin{array}{l}\text { Afirma que ferramentas como o Lean e o Seis Sigma podem ser altamente } \\
\text { eficazes para enfrentar os complexos desafios que confrontam os cuidados da } \\
\text { área saúde. Sugere que a cultura organizacional da maioria dos hospitais norte- } \\
\text { americanos e outras instituições de saúde devem mudar. }\end{array}$ & 11 \\
\hline \multirow{2}{*}{$\frac{⿱}{\circ}$} & $\begin{array}{l}\text { Gijo, E. V.; Antony, } \\
\text { Jiju (2014) }\end{array}$ & $\begin{array}{l}\text { Este artigo aborda a questão do tempo de espera mais paciente no ambulatório } \\
\text { de um hospital indiano, por meio da metodologia LSS. Como resultado deste } \\
\text { projeto, o tempo médio de espera reduzido de } 57 \mathrm{~min} \text { para } 24 \mathrm{~min} \text { e o desvio } \\
\text { padrão foi reduzida para } 9 \text { a partir de } 31 \mathrm{~min} \text {. }\end{array}$ & 0 \\
\hline & $\begin{array}{l}\text { d'Young, A. I.; } \\
\text { Young, L.; } \\
\text { Ockelford, P. A.; et } \\
\text { al. (2014) }\end{array}$ & $\begin{array}{l}\text { Este artigo tem por objetivo melhorar o número e a velocidade com que episódios } \\
\text { hemorrágicos eram notificados. Trabalhou-se com } 70 \text { adultos vivendo na região } \\
\text { de Auckland da Nova Zelândia com hemofilia moderada e severa. Reduziu-se o } \\
\text { número de episódios hemorrágicos reportados de um limite pré-especificado de } \\
\text { tempo de } 48 \mathrm{~h} \text { em } 68 \% \text {. }\end{array}$ & 0 \\
\hline
\end{tabular}

Fonte: Os autores

Destacaram-se da mesma forma, as palavras-chave com referência a metodologia da pesquisa, tais como "Case" e "Study" referindo-se ao Estudo de Caso, abordagem preferida pelos autores (seção 4.3). Além de aplicações na área da saúde, a Tabela 3 mostra exemplos de publicações relacionadas à temáticas diversas, como a aplicação do LSS na gestão de serviços e áreas administrativas de um modo geral, implementação do LSS em pequenas e médias empresas. 
Tabela 3 - Publicações da amostra divididas por áreas de pesquisa

\begin{tabular}{|c|c|c|}
\hline Temática & Artigo & Descrição \\
\hline $\begin{array}{c}\text { Serviços } \\
\text { Bancários }\end{array}$ & $\begin{array}{l}\text { Wang, Fu- } \\
\text { Kwun; Chen, } \\
\text { Kao-Shan } \\
(2010)\end{array}$ & $\begin{array}{l}\text { Neste estudo, os autores buscaram expandir a abordagem LSS para uma aplicação mais ampla } \\
\text { no setor de serviços e integrar metodologia TRIZ (Theoria Resheneyva Isobretatelskehuh } \\
\text { Zadach) para aprimorar as técnicas tradicionais de LSS. TRIZ é um método eficaz para analisar } \\
\text { as necessidades dos clientes e desenvolver soluções inovadoras para atender a essas } \\
\text { necessidades. A metodologia foi aplicada a um problema de serviços bancários. Os resultados } \\
\text { mostram que a aplicação da metodologia LSS com TRIZ realiza efetivamente na melhoria desse } \\
\text { processo. }\end{array}$ \\
\hline $\begin{array}{l}\text { Indústria de } \\
\text { aviões }\end{array}$ & $\begin{array}{l}\text { Akbulut-Bailey, } \\
\text { Asli Yagmur; } \\
\text { Motwani, } \\
\text { Jaideep; } \\
\text { Smedley, } \\
\text { Everett M. } \\
\text { (2012) }\end{array}$ & $\begin{array}{l}\text { Segundo os autores, as técnicas que parecem mais promissoras para melhorar a produtividade } \\
\text { e serviço ao cliente, a fim de competir com êxito para alcançar resultados de classe mundial são } \\
\text { o Lean e o Seis Sigma. Neste trabalho, por meio de um estudo de caso detalhado, } \\
\text { demonstramos como uma grande empresa de fabricação de aeronaves localizado no oeste de } \\
\text { Michigan incorporou com sucesso o conceito LLS em suas operações. Discute-se os fatores que } \\
\text { facilitaram o sucesso do LLS e são fornecidas sugestões para os gestores que estão pensando } \\
\text { em implementar esta estratégia de melhoria. }\end{array}$ \\
\hline $\begin{array}{l}\text { Indústria } \\
\text { automotiva } \\
\text { da Îndia }\end{array}$ & $\begin{array}{l}\text { Habidin, N. F.; } \\
\text { Yusof, S. M. } \\
\text { (2012) }\end{array}$ & $\begin{array}{l}\text { O objetivo deste relatório é o de investigar e realizar a análise estrutural do LSS e Desempenho } \\
\text { Organizacional (OP). Os dados foram obtidos a partir de } 252 \text { líderes de gestão de topo na } \\
\text { indústria automotiva da Malásia. O principal objetivo da análise foi fornecer esclarecimentos } \\
\text { adicionais sobre a relação entre LSS e OP examinando os efeitos da certificação ISO } 14001 \\
\text { como moderador. Os resultados indicam que a certificação ISO } 14001 \text { não abrandam } \\
\text { significativamente a relação entre LSS e OP na indústria automotiva da Malásia. }\end{array}$ \\
\hline $\begin{array}{l}\text { Indústria de } \\
\text { manutenção } \\
\text { de motores } \\
\text { de avião }\end{array}$ & $\begin{array}{l}\text { Shanmuganatha } \\
\text { n, V. K.; Haran, } \\
\text { A. P.; } \\
\text { Ragavendran, } \\
\text { S.; et al. (2013) }\end{array}$ & $\begin{array}{l}\text { Trata-se de um estudo da implementação de princípios do LSS em uma indústria de } \\
\text { manutenção de motores de aeronaves. Segundo os autores, o custo de manutenção de } \\
\text { aeronaves é de } 12 \% \text { do custo total de operação. Portanto, a capacidade de sobrevivência de } \\
\text { indústrias de avião baseia-se na sua capacidade de otimizar custos de operação, eliminando } \\
\text { desperdícios de mão-de-obra, máquinas e materiais. }\end{array}$ \\
\hline $\begin{array}{l}\text { Indústria da } \\
\text { construção }\end{array}$ & $\begin{array}{l}\text { Anderson, } \\
\text { Nicole C.; } \\
\text { Kovach, } \\
\text { Jamison V. } \\
\text { (2014) }\end{array}$ & $\begin{array}{l}\text { Trata-se de um estudo aplicado à indústria da construção, que utiliza a metodologia LSS para } \\
\text { reduzir defeitos de soldagem em projetos, evitando atrasos no cronograma, e levando, portanto, } \\
\text { a satisfação do cliente. Como resultado, apresentou-se melhorarias no desempenho do projeto. } \\
\text { A partir de uma perspectiva mais ampla, esta pesquisa demonstra como o LSS pode ser } \\
\text { aplicado em ambientes de serviços. Ele também fornece evidências dos benefícios tangíveis } \\
\text { que podem ser alcançados dentro de operações de construção da especialidade, utilizando } \\
\text { estratégias de melhoria de processos. }\end{array}$ \\
\hline $\begin{array}{l}\text { (Pequenas e } \\
\text { Médias } \\
\text { Empresas) } \\
\text { PME }\end{array}$ & $\begin{array}{l}\text { Sharma, Rajiv } \\
\text { Kumar; Sharma, } \\
\text { Rajan Gopal } \\
\text { (2014) }\end{array}$ & $\begin{array}{l}\text { Os resultados envolvendo entrevistas e grupos de discussão informaram o desenvolvimento de } \\
\text { um modelo analítico demonstrando a dinâmica de rotinas para o processo de capacidade de } \\
\text { absorção e o desenvolvimento de uma série de proposições relativas às características de a } \\
\text { implementação do Seis Sigma e do LSS em PME. }\end{array}$ \\
\hline
\end{tabular}

Fonte: Os autores

\subsection{Análise de redes sociais}

$\mathrm{Na}$ busca de identificação das bases teóricas sobre as quais a amostra de publicações foi desenvolvida, construiu-se uma rede de relacionamento entre os artigos da amostra e suas referências. O resultado dessa primeira análise está demonstrado na Figura 7. Dentre os artigos da amostra, aparecem estudos de casos, em que realizam-se implementações do LSS a setores diversos; aplicações do LSS à área da Saúde, artigos sobre Seis Sigma, conforme ilustrados. 
Figura 7 - Rede de relacionamento entre os artigos da amostra e suas referências

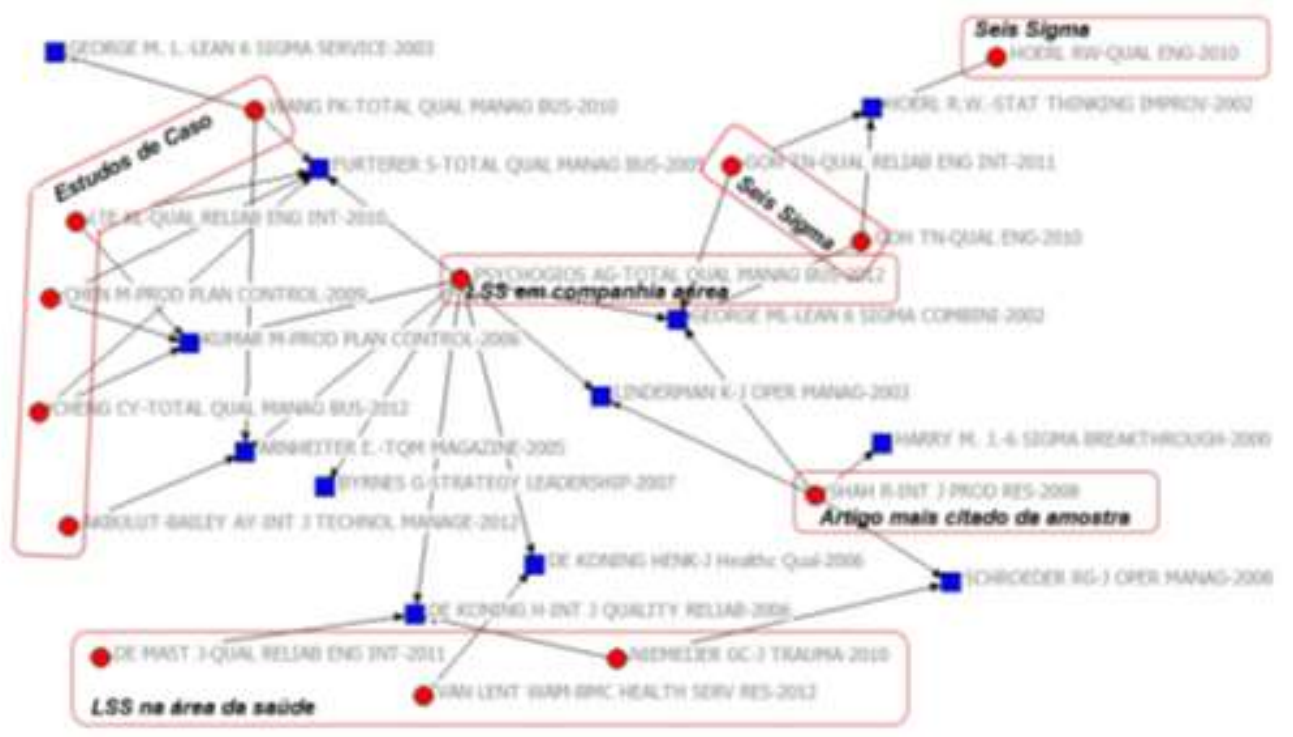

Fonte: Os autores

Nota: Os círculos representam os artigos da amostra inicial citados no mínimo três vezes. Os quadrados, representam suas referências, citadas por no mínimo cinco artigos

Realizou-se a análise de cocitação, a fim de medir o grau de ligação entre dois ou mais artigos pelo número de documentos que os citam. A rede de cocitação da Figura 8 relaciona as citações-referências usadas por pelo menos três artigos da amostra.

Figura 8 - Rede de cocitação

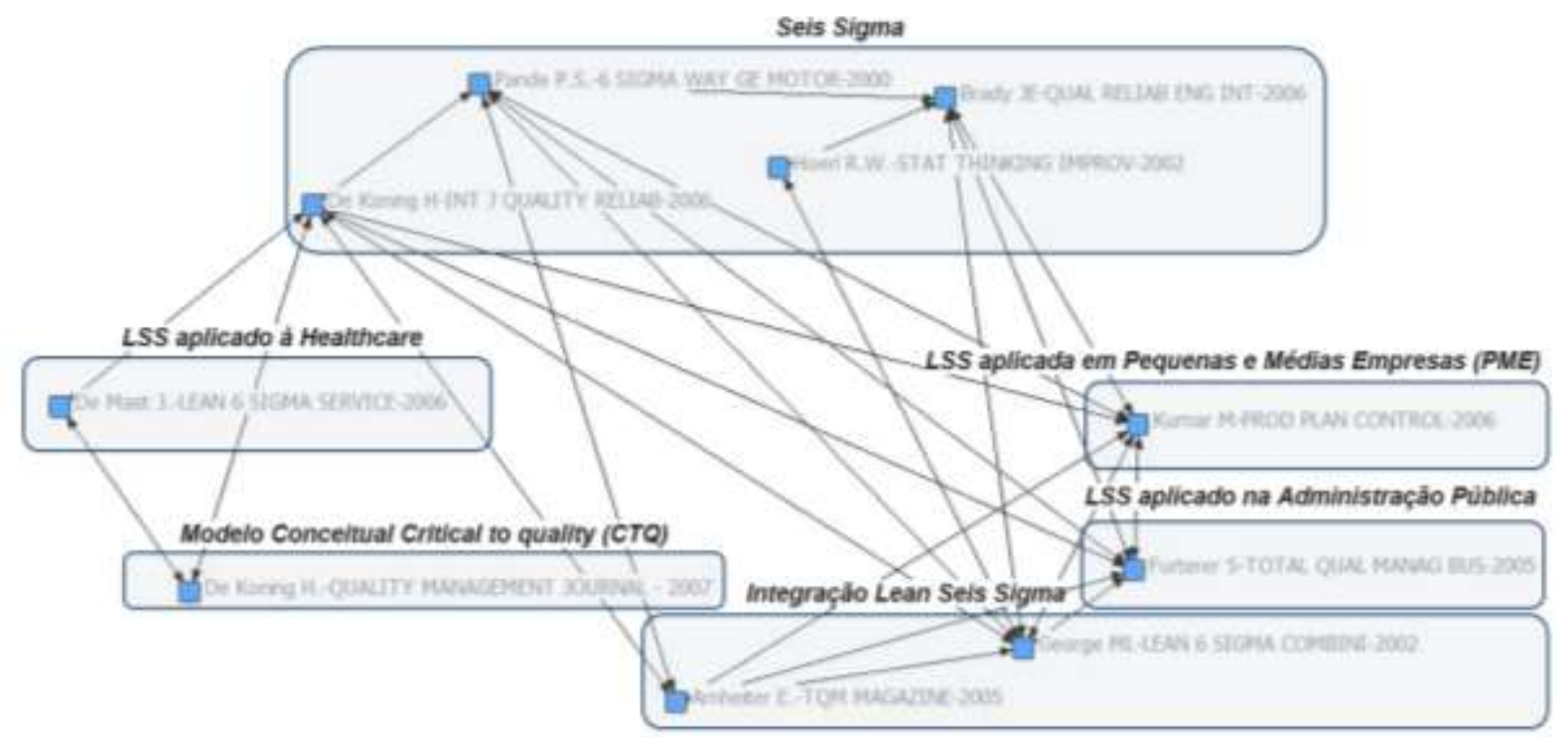

Fonte: Os autores

Nota: Os quadrados representam as referências dos artigos da amostra que foram citadas conjuntamente pelo menos três vezes. 
Os resultados dessas análises evidenciaram agrupamentos relacionados a diversas temáticas. Embora, não tenha se evidenciado nenhuma concentração de destaque, pode-se considerar os trabalhos apresentados na Tabela 4 como pilares teóricos da temática do LSS. Estes estudos, não pertencentes à amostra, são de grande importância para utilização tanto como suporte metodológico para pesquisas qualitativas como para estudos de casos.

Tabela 4 - Descrição de publicações consideradas como pilares teóricos ao LSS e suas temáticas

\begin{tabular}{|c|c|c|}
\hline Referência & Descrição & Temáticas \\
\hline $\begin{array}{l}\text { HOERL, R.; SNEE, R.D. Statistical } \\
\text { Thinking: Improving Business } \\
\text { Performance. Pacific Grove, CA, } \\
\text { Duxburry, } 2002 .\end{array}$ & $\begin{array}{l}\text { Trata-se de um livro sobre o Pensamento Estatístico, e como ele pode ajudar a tomar } \\
\text { decisões cruciais nos negócios. Mostra-se como tirar conclusões a partir da análise de } \\
\text { dados e como melhorar os processos reais, através de estudos de casos. }\end{array}$ & $\begin{array}{l}\text { Pensamento } \\
\text { Estatístico }\end{array}$ \\
\hline $\begin{array}{l}\text { GEORGE, M. Lean six sigma: } \\
\text { combining six sigma quality with } \\
\text { Lean production speed. } 2002 .\end{array}$ & $\begin{array}{l}\text { Este livro consiste em um guia prático para integrar Lean e Seis Sigma, que } \\
\text { separadamente, têm mudado a face de negócios de fabricação. Mas, que juntos, } \\
\text { segundo o autor, tornam-se uma ferramenta sem precedentes para melhorar a } \\
\text { qualidade de produtos, a eficiência de processos e a rentabilidade geral. }\end{array}$ & \multirow[b]{2}{*}{ Integração LSS } \\
\hline $\begin{array}{l}\text { ARNHEITER, E.D.; MALEYEFF, J. } \\
\text { The integration of Lean } \\
\text { management and Six Sigma. The } \\
\text { TQM magazine, v. } 17, \text { n. } 1 \text {, p. 5-18, } \\
2005 .\end{array}$ & $\begin{array}{l}\text { Para eliminar muitos equívocos sobre Seis Sigma e gestão Lean, descreve-se cada } \\
\text { sistema e os principais conceitos e técnicas que fundamentam a sua aplicação. } \\
\text { Segundo os autores, a execução conjunta dos programas resulta em uma organização } \\
\text { LSS, superando as limitações de cada programa quando implementadas de forma } \\
\text { isolada. }\end{array}$ & \\
\hline $\begin{array}{l}\text { GEORGE, M.L. Lean six sigma for } \\
\text { service. New York, NY: McGraw- } \\
\text { Hill, } 2003 .\end{array}$ & $\begin{array}{l}\text { Este livro dedica quase todas as aplicações de LSS para serviços, aplicando vários } \\
\text { estudos de caso tão eficazmente como na manufatura e com resultados ainda mais } \\
\text { rápidos. Aqui, apresenta-se ferramentas como "sistema puxado" e "redução de setup" } \\
\text { utilizados em contratações, compras, call centers, salas de cirurgia, escritórios do } \\
\text { governo, etc. }\end{array}$ & Serviços \\
\hline $\begin{array}{l}\text { FURTERER, S.; ELSHENNAWY, A. K. } \\
\text { Implementation of TQM and Lean } \\
\text { Six Sigma tools in local } \\
\text { government: a framework and a } \\
\text { case study.Total Quality } \\
\text { Management \& Business } \\
\text { Excellence, v. 16, n. 10, p. } 1179- \\
1191,2005 .\end{array}$ & $\begin{array}{l}\text { A maioria dos aplicações de TQM e LSS têm sido na indústria privada, com foco } \\
\text { principalmente em aplicações de fabricação. A literatura não forneceu casos de } \\
\text { programas de LSS aplicados ao governo local. Este artigo apresenta alguns esforços de } \\
\text { implementação de ferramentas de TQM no governo local e um estudo de caso de } \\
\text { aplicação de ferramentas e princípios LSS para a melhoria da qualidade e } \\
\text { oportunidade de fornecer serviços governamentais locais. }\end{array}$ & $\begin{array}{l}\text { Administração } \\
\text { Pública }\end{array}$ \\
\hline $\begin{array}{l}\text { KUMAR, M. et al. Implementing } \\
\text { the Lean Sigma framework in an } \\
\text { Indian SME: a case } \\
\text { study. Production Planning and } \\
\text { Control, v. } 17, \text { n. } 4 \text {, p. } 407-423 \text {, } \\
2006 .\end{array}$ & $\begin{array}{l}\text { Este artigo propõe uma estrutura LSS para reduzir a ocorrência de defeitos em } \\
\text { acessórios de automóveis, mais especificamente, no produto final de um processo de } \\
\text { fundição. O quadro proposto integra ferramentas Lean (mapa do estado atual, 5S e } \\
\text { Manutenção Produtiva Total (TPM)) dentro de metodologia Seis Sigma DMAIC. Como } \\
\text { resultados, constata-se melhoria no número de defeito por unidade (DPU) e uma } \\
\text { consequente economia financeira considerável. }\end{array}$ & PME \\
\hline $\begin{array}{l}\text { DE KONING, H. et al. Lean six } \\
\text { sigma in healthcare. Journal for } \\
\text { Healthcare Quality, v. 28, n. 2, p. } \\
4,2006 .\end{array}$ & $\begin{array}{l}\text { Este artigo descreve uma metodologia e apresenta exemplos para ilustrar como os } \\
\text { princípios do Lean e do Seis Sigma podem ser combinados para fornecer um quadro } \\
\text { eficaz para a produção de esforços sistemáticos em saúde. Controlar aumentos de } \\
\text { custos, melhorando a qualidade, e fornecendo melhores cuidados de saúde são } \\
\text { alguns dos benefícios desta abordagem. }\end{array}$ & \multirow[t]{2}{*}{ Healthcare } \\
\hline $\begin{array}{l}\text { DE MAST, J.; DOES, R. J. M. M.; DE } \\
\text { KONING, H. Lean Six Sigma for } \\
\text { service and healthcare. Beaumont } \\
\text { Quality Publications, 2006. }\end{array}$ & $\begin{array}{l}\text { Este livro centra-se sobre a aplicação do LSS em Serviço e Saúde. Os autores } \\
\text { trabalham para o Institute for Business and Industrial Statistics. Esta é uma empresa } \\
\text { de consultoria e pesquisa instituto de propriedade da Universidade de Amsterdã. }\end{array}$ & \\
\hline $\begin{array}{l}\text { DE KONING, H.; DE MAST, J. A } \\
\text { rational reconstruction of Six- } \\
\text { Sigma's breakthrough } \\
\text { cookbook. International Journal of } \\
\text { Quality \& Reliability Management, } \\
\text { v. } 23, \text { n. } 7 \text {, p. } 766-787,2006 .\end{array}$ & $\begin{array}{l}\text { O propósito deste artigo é desenvolver uma exposição consistente e cristalizada de } \\
\text { metodologia do Seis Sigma para projetos de melhoria, o que poderia servir de base } \\
\text { para a subsequente investigação científica do método. A reconstrução descritiva dos } \\
\text { principais elementos do método Seis Sigma é realizada: seu contexto de negócios, } \\
\text { estratégia, ferramentas e técnicas e conceitos e classificações. }\end{array}$ & \multirow{2}{*}{ Seis Sigma } \\
\hline $\begin{array}{l}\text { SCHROEDER, R. G. et al. Six Sigma: } \\
\text { Definition and underlying theory. } \\
\text { Journal of operations } \\
\text { Management, v. } 26, \text { n. } 4 \text {, p. } 536- \\
554,2008 .\end{array}$ & $\begin{array}{l}\text { Seis Sigma é um fenômeno que está a ganhar grande aceitação na indústria, mas } \\
\text { carece de uma base teórica e uma base para a pesquisa além de estudos das } \\
\text { "melhores práticas". Este trabalho desenvolve uma compreensão dos fenômenos Seis } \\
\text { Sigma partir de uma perspectiva teórica objetiva. Após revisão da literatura, sugere-se } \\
\text { algumas proposições para futuras pesquisas. Este busca contribuir com uma base para } \\
\text { o desenvolvimento do conhecimento científico sobre Seis Sigma. }\end{array}$ & \\
\hline
\end{tabular}

Fonte: Os autores

Revista Produção Online, Florianópolis, SC, v. 16, n. 2, p. 575-605, abr./jun. 2016. 


\subsection{Abordagens metodológicas}

Este item analisa as abordagens metodológicas preferidas pelos autores. Primeiramente, apresenta-se um quadro que categoriza a literatura em teórica ou empírica, e prescritiva ou descritiva (em termos percentuais) em quatro quadrantes (Figura 9).

Figura 9 - Quadro de classificação de literatura de acordo com a metodologia

\begin{tabular}{|c|c|c|}
\hline & Prescritivo & Descritivo \\
\hline Teórico & $12,5 \%$ & $17,5 \%$ \\
\hline Empírico & $5 \%$ & $65 \%$ \\
\hline
\end{tabular}

Fonte: Os autores

Nessa análise, evidencia-se que a literatura é dominada por estudos empíricos descritivos. Aproximadamente $70 \%$ dos trabalhos produzidos são empíricos, ou seja, relatórios de aplicação no LSS em determinado segmento. Destes, $65 \%$ são descritivos - tratam-se de estudos que explanam e sumarizam práticas existentes do LSS. Os $5 \%$ restantes, com suas aplicações, propõem modelos ou práticas a serem adotadas pelas empresas.

São exemplos de trabalhos empíricos prescritivos os trabalhos de Karthi, et al. (2013), sobre a implementação do LSS através da ISO 9001 em uma fábrica têxtil, o trabalho de Rodney, et al. (2014) sobre pequenas e médias empresas e o de Stanton, et al. (2014) que analisa o LSS num departamento de emergência de um hospital australiano.

Em relação aos trabalhos teóricos, que compõem 30\% dos artigos da amostra, há um certo equilíbrio entre os prescritivos (12,5\%) e descritivos (17,5\%). Os estudos de Shah; Chandrasekaran e Linderman (2008) e Drohomeretski, et al. (2014), já mencionados, e os estudos de Chassin (2013) e Chiarini e Bracci (2013), da área da saúde, são excelentes exemplos de trabalhos dessa categoria, que tem por característica fornecer explicações de causa e efeito, definir leis subjacentes, ou propor conceitos analíticos (CROOM; ROMANO; GIANNAKIS, 2000).

Para que se pudesse ter uma ideia da predominância de determinados métodos de pesquisa pelos pesquisadores do LSS, apresenta-se a Figura 10. Para fazer esta análise, foram utilizadas as informações fornecidas pelos próprios autores sobre o método que eles seguiram sem julgar eventuais incoerências, visto que se trata de artigos aprovados em periódicos que possuem procedimentos de revisão. 
Figura 10 - Abordagens metodológicas ao longo dos anos

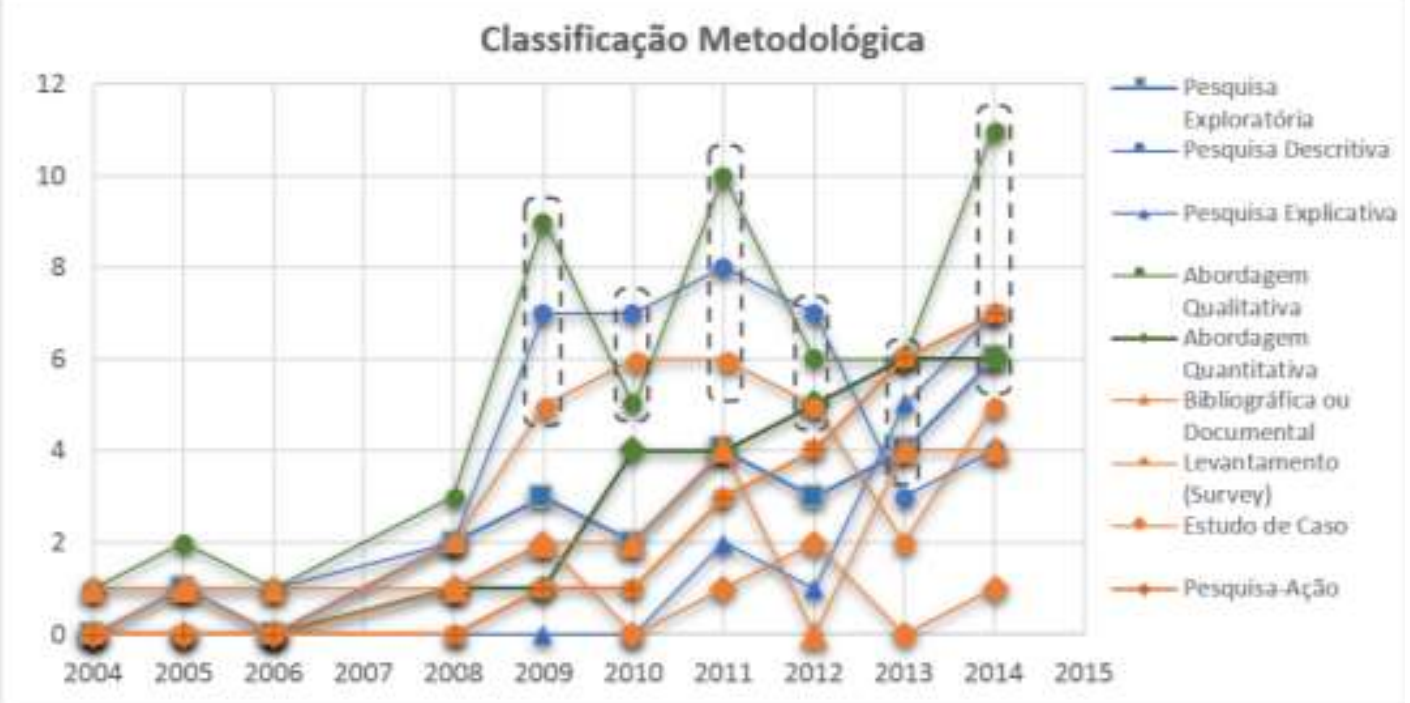

Fonte: Os autores

Quanto aos objetivos, as pesquisas apresentam até o ano 2012, em sua maioria, caráter descritivo, o que significa que visavam descrever características de determinado fenômeno. Nos anos seguintes, verifica-se pesquisas explicativas, que identificam fatores que determinam ou que contribuem para a ocorrência dos fenômenos (GIL, 2009).

Quanto aos procedimentos, constata-se uma predominância de pesquisas de do tipo Estudo de Caso (simples ou múltiplos) e Pesquisa-Ação (cerca de 69\% do total da amostra), decorrente do fato de que o LSS consiste, propriamente, em uma metodologia de melhoria de processos aplicável em diversos segmentos (PRODANOV, FREITAS, 2013).

Em relação à abordagem do problema, a maioria dos artigos investigados adota o enfoque qualitativo (66\%). Tal fato denota que os artigos analisados "preocupam-se muito mais com o processo do que com o produto" (PRODANOV, FREITAS, 2013, p.70), ou seja, importam-se mais com as formas de implantação do LSS do que com os valores dos ganhos financeiros e de produtividade obtidos, por exemplo.

\subsection{Tendências de estudo na literatura}

Autores acreditam que as organizações precisam de um guia/modelo para a implementação do LSS para cada segmento empresarial (público, de fabricação, de serviços, cuidados de saúde, ensino superior, por exemplo) e para diferentes Revista Produção Online, Florianópolis, SC, v. 16, n. 2, p. 575-605, abr.jun. 2016. 
tamanhos das organizações (pequenas, médias e grandes) (ALBLIWI, 2014; CHAKRAVORTY, 2009; KUMAR et al., 2011; PEPPER e SPEDDING, 2010). Especialmente para organizações que desejam iniciar o LSS a partir do zero, que sentem dificuldade em saber como começar (KUMAR et al., 2009).

Uma possível tendência de estudos futuros refere-se a uma direção em particular que o LSS poderia evoluir: o Green Lean Sigma (GLS) que seria uma interpretação ambiental do LSS (MARSH E PERERA, 2011). Esta metodologia nova e inovadora já existe em uma variedade de formas, tais como Green Sigma (OLSON e BRADY, 2009) desenvolvido pela IBM ou kit de ferramentas do Lean Environment (REED et al., 2007, apud MARSH e PERERA, 2011) desenvolvido pela Agência de Proteção Ambiental dos EUA.

Por fim, outra tendência de estudos é referente a criação de novos softwares estatísticos. De acordo com Marsh e Perera (2011), o software mais comumente utilizado é o Minitab ${ }^{\circledR}$. Poderia-se projetar softwares com interfaces gráficas mais amigáveis de modo a facilitar a comunicação com todas as partes interessadas.

\section{CONSIDERAÇÕES FINAIS}

As análises descritivas das publicações foram utilizadas para traçar um panorama geral das mesmas. Evidenciando-se os autores que mais publicam sobre o tema, não pôde-se apontar pesquisadores com histórico de pesquisa relevante, pelo contrário, a amostra apresentou uma dispersão considerável dentre vários autores. Tal fato induz a uma possível falta de maturidade da temática LSS.

Ainda sobre as características de autoria dos trabalhos sobre o LSS, artigos com 3 ou mais autores compõe $51 \%$ do total de artigos da amostra, enquanto artigos individuais compõem apenas 19\%. Tal fato, pode ser indicativo da existência de grupos de pesquisa sobre a temática. Um autor evidencia-se nessa análise: Jiju Antony, de Edimburgo, Escócia.

Constatou-se que existe um predomínio acentuado de publicações originárias dos Estados Unidos (40\% do total), sendo que o Brasil possui apenas uma única publicação. O periódico de maior destaque em volume de publicações é o Total Quality Management Business Excellence, seguido do Quality and Reliability Engineering International, Quality Engineering. 
$\mathrm{Na}$ análise dos métodos de pesquisa dos artigos, atestou-se quanto aos objetivos, que as pesquisas, em sua maioria, possuem caráter descritivo, o que significa que visam descrever características de determinado fenômeno. Quanto aos procedimentos, apresentam uma predominância de pesquisas do tipo Estudo de Caso (simples ou múltiplos) e Pesquisa-Ação (cerca de $69 \%$ do total da amostra). Em relação à abordagem do problema, a maioria dos artigos investigados adota o enfoque qualitativo (66\%).

Evidencia-se que a literatura é dominada por estudos empíricos descritivos. Estudos empíricos são de grande valor, no entanto, um corpo teórico fundamentado pode inclusive contribuir com a aplicação eficaz do LSS. Sob essa configuração contextual, a academia tem um papel crucial a desempenhar - preencher essa lacuna entre teoria e a prática. Como principais temáticas tem-se a área da saúde, seguida do emprego do LSS na gestão de serviços e áreas administrativas de um modo geral, e aplicações em pequenas e médias empresas.

Acredita-se que o referido trabalho tenha contribuído para a consolidação do conhecimento disponível, contribuindo para a continuidade das investigações. Fazse necessário, porém, mostrar algumas limitações do método e das fontes de dados que estão disponíveis para a construção de trabalhos dessa natureza nos dias de hoje.

A plataforma escolhida para esta investigação, ISI Web of Science, tem a predominância de publicações norte-americanas e em língua inglesa, não contemplando a produção acadêmica de muitos países, sobretudo aqueles em desenvolvimento. Sendo assim, publicações brasileiras, relevantes para o entendimento do problema de pesquisa não necessariamente integram a amostra utilizada, e por consequência, não estão retratadas nos resultados.

Outra limitação, originada também do processo amostral, diz respeito ao tipo de publicações selecionadas. Livros sobre o LSS, por exemplo, não são muito comuns nas fontes de dados. Ou seja, o conhecimento que não tenha sido transformado em um artigo científico não foi levado em consideração nesta pesquisa. O que se sugere, então, é o desenvolvimento de uma investigação, cuja amostra seja constituída por artigos publicados no Brasil, ainda que não se considere outros veículos de publicação, mas que seja possível a identificação de autores e núcleos de pesquisa com produção relevante no país. 
A metodologia LSS pode ser considerada recente, logo, o campo para novas pesquisas na área é bastante amplo. Como tendências de estudos para trabalhos futuros, pode-se apostar em uma interpretação ambiental aplicada ao LSS ou mesmo na criação de novos softwares estatísticos. No entanto, ainda existem muitas lacunas referentes a aplicação do LSS nos diversos segmentos de mercado. Por exemplo, pesquisas que identificam fatores de sucesso de projetos LSS estratificados em relação: a diferentes tipos de empresas, como do setor público ou particular, de serviços ou produto; ou aos diferentes tamanhos de organizações; à diferente evolução do país em que se situa (desenvolvidos ou em desenvolvimento); constituem-se em oportunidades evidentes para pesquisas futuras neste ambiente.

\section{REFERÊNCIAS}

AAKRE, K.T.; VALLEY, T.B.; O'CONNOR, Michael K. Quality Initiatives: Improving Patient Flow for a Bone Densitometry Practice: Results from a Mayo Clinic Radiology Quality Initiative 1. Radiographics, v. 30, n. 2, p. 309-315, 2010.

http://dx.doi.org/10.1148/rg.302095735

AKBULUT-BAILEY, A.Y.; MOTWANI, J.; SMEDLEY, E.M. When Lean and Six Sigma converge: a case study of a successful implementation of Lean Six Sigma at an aerospace company. International Journal of Technology Management, v. 57, n. 1/2/3, p. 18-32, 2012. http://dx.doi.org/10.1504/ijtm.2012.043949

ALBLIWI, S.; ANTONY, J.; ABDUL HALIM LIM, S.; VAN DER WIELE, T. Critical failure factors of Lean Six Sigma: a systematic literature review. International Journal of Quality \& Reliability Management, v. 31, n. 9, p. 1012-1030, 2014. http://dx.doi.org/10.1108/ijarm-09$\underline{2013-0147}$

ANDERSON, N.C.; KOVACH, J.V. Reducing welding defects in turnaround projects: a Lean Six Sigma case study. Quality Engineering, v. 26, n. 2, p. 168-181, 2014.

ANTONY, J. Six Sigma for service processes. Business Process Management Journal, v. 12 n. 2, p. 234-48, 2006. http://dx.doi.org/10.1108/14637150610657558

ANTONY, J.; KRISHAN, N.; CULLEN, D.; KUMAR, M. Lean Six Sigma for higher education institutions (HEls): challenges, barriers, success factors, tools/techniques. International Journal of Productivity and Performance Management, v. 61, n. 8, p. 940-948, 2012. http://dx.doi.org/10.1108/17410401211277165

ANTONY, J.; KUMAR, M.; MADU, C.N. Six sigma in small- and medium-sized UK manufacturing enterprises: some empirical observations. International Journal of Quality \& Reliability Management, v. 22, n. 8, p. 860-874, 2005.

http://dx.doi.org/10.1108/02656710510617265

ARNHEITER, E.D.; MALEYEFF, J. The integration of Lean management and Six Sigma. The TQM magazine, v. 17, n. 1, p. 5-18, 2005. http://dx.doi.org/10.1108/09544780510573020

BENDELL, T. A review and comparison of six sigma and the Lean organizations. The TQM Magazine, v. 18, n. 3, p. 255-62, 2006. http://dx.doi.org/10.1108/09544780610659989 
BHASIN, S.; BURCHER, P. Lean viewed as a philosophy. Journal of Manufacturing Technology Management, v. 17, n. 1, p. 56-72, 2006.

http://dx.doi.org/10.1108/17410380610639506

BORGATTI, S.P.; EVERETT, M.G.; FREEMAN, L.C. Ucinet for Windows: Software for social network analysis, 2002.

BREYFOGLE III, F.W. Next-generation management Going beyond Lean Six Sigma and the balanced scorecard. Industrial Engineer, v. 41, n. 12, p. 24-29, 2009.

BYRNE, G.; LUBOWE, D.; BLITZ, A., Using a Lean Six Sigma approach to drive innovation. Strategy \& Leadership, v. 35, n. 2, p. 5-10, 2007.

http://dx.doi.org/10.1108/10878570710734480

CALDWELL, C. A high quality of care Lean Six Sigma makes the rounds in health systems with strong leadership. Industrial engineer, v. 37, n. 9, p. 44-48, 2005.

CARVALHO, M.; FLEURY, A.; LOPES, A.P. An overview of the literature on technology roadmapping (TRM): contributions and trends. Technological Forecasting and Social Change, v. 80, n. 7, p. 1418-1437, 2013. http://dx.doi.org/10.1016/j.techfore.2012.11.008

CHAKRAVORTY, S.S. Six Sigma programs: an implementation model. International Journal of Production Economics, v. 119, n. 1, p. 1-16, 2009.

http://dx.doi.org/10.1016/j.ijpe.2009.01.003

CHASSIN, M.R. Improving The Quality Of Health Care: What's Taking So Long? Health

Affairs, v. 32, n. 10, p. 1761-1765, 2013. http://dx.doi.org/10.1377/hlthaff.2013.0809

CHASSIN, R. The Six Sigma initiative at Mount Sinai medical center. Mount Sinai Journal of Medicine, v. 75, n. 1, p. 45-52, 2008. http://dx.doi.org/10.1002/msj.20011

CHEN, M.; LYU, Jung. A Lean Six-Sigma approach to touch panel quality improvement. Production Planning and Control, v. 20, n. 5, p. 445-454, 2009.

http://dx.doi.org/10.1080/09537280902946343

CHENG, C.; CHANG, P. Implementation of the Lean Six Sigma framework in non-profit organizations: A case study. Total Quality Management \& Business Excellence, v. 23, n. 3-4, p. 431-447, 2012. http://dx.doi.org/10.1080/14783363.2012.663880

CHIARINI, A.; BRACCI, E. Implementing Lean Six Sigma in healthcare: issues from Italy. Public Money \& Management, v. 33, n. 5, p. 361-368, 2013.

http://dx.doi.org/10.1080/09540962.2013.817126

CROOM, S.; ROMANO, P.; GIANNAKIS, M. Supply chain management: an analytical framework for critical literature review. European journal of purchasing \& supply management, v. 6, n. 1, p. 67-83, 2000. http://dx.doi.org/10.1016/s0969-7012(99)00030-1

DOES, R.J.; VERMAAT, T.M.; VERVER, J.P.; BISGAARD, S.; VAN DEN HEUVEL, J.

Reducing start time delays in operating rooms. Journal of Quality Technology, v. 41, n. 1, p. 95-109, 2009.

DROHOMERETSKI, E.; DA COSTA, S.E.G.; DE LIMA, E.P.; GARBUIO, P. A.R. Lean, Six Sigma and Lean Six Sigma: an analysis based on operations strategy. International 
Journal of Production Research, v. 52, n. 3, p. 804-824, 2014.

http://dx.doi.org/10.1080/00207543.2013.842015

DUARTE, B.; MONTGOMERY, D.; FOWLER, J.; KONOPKA, J. Deploying LSS in a global enterprise - project identification. International Journal of Lean Six Sigma, v. 3, n. 3, p. 187-205, 2012. http://dx.doi.org/10.1108/20401461211282709

D'YOUNG, A. I.; YOUNG, L.; OCKELFORD, P.A.; BRASSER, M.; SLAVIN, K.; MANSON, L.; PRESTON, S. The use of a co-design model in improving timely bleed reporting by adults with haemophilia living in the Auckland region of New Zealand. Haemophilia, v. 20, n. 3, p. 388-397, 2014. http://dx.doi.org/10.1111/hae.12336

FURTERER, S.; ELSHENNAWY, A. K. Implementation of TQM and Lean Six Sigma tools in local government: a framework and a case study. Total Quality Management \& Business

Excellence, v. 16, n. 10, p. 1179-1191, 2005. http://dx.doi.org/10.1080/14783360500236379

GEORGE, M.L. Lean six sigma for service. New York, NY: McGraw-Hill, 2003.

GEORGE, M.L. Lean Six Sigma: combining Six Sigma Quality with Lean speed. New York: McGraw-Hill, 2002.

GIJO, E. V.; ANTONY, J. Reducing patient waiting time in outpatient department using Lean six sigma methodology. Quality and Reliability Engineering International, v. 30, n. 8, p. 1481-1491, 2014. http://dx.doi.org/10.1002/qre.1552

GIL, A.C. Como elaborar projetos de pesquisa. 4 ed. Atlas: São Paulo, 2009.

GLASGOW, J.M.; CAZIEWELL, S.; JILL, R.; KABOLI, P.J. Guiding inpatient quality improvement: a systematic review of Lean and Six Sigma. Joint Commission Journal on Quality and Patient Safety, v. 36, n. 12, p. 533-540, 2010.

GOH, T.N. Six Sigma in industry: some observations after twenty-five years. Quality and Reliability Engineering International, v. 27, n. 2, p. 221-227, 2011.

http://dx.doi.org/10.1002/are.1093

HABIDIN, N.F.; YUSOF, S.M. Relationship between Lean six sigma, environmental management systems, and organizational performance in the Malaysian automotive industry. International Journal of Automotive Technology, v. 13, n. 7, p. 1119-1125, 2012. http://dx.doi.org/10.1007/s12239-012-0114-4

HOERL, R.; SNEE, R.D. Statistical Thinking: Improving Business Performance. Pacific Grove, CA, Duxburry, 2002.

HOERL, R.W.; SNEE, R. Statistical thinking and methods in quality improvement: A look to the future. Quality Engineering, v. 22, n. 3, p. 119-129, 2010.

http://dx.doi.org/10.1080/08982112.2010.481485

JING, G.G. A Lean Six Sigma breakthrough, quality progress. American Society of Quality. p. 24-31, 2009.

KANDEBO, S.W. Lean, Six Sigma yield dividends for C-130J. Aviation Week \& Space Technology, v. 151, n. 2, p. 59-61, 1999. 
KONING, H.; DE MAST, J. A rational reconstruction of Six-Sigma's breakthrough cookbook. International Journal of Quality \& Reliability Management, v. 23, n. 7, p. 766-787, 2006. http://dx.doi.org/10.1108/02656710610701044

KONING, H.; VERVER, J. P.; VAN DEN HEUVEL, J.; BISGAARD, S.; DOES, R. J. M. M. Lean six sigma in healthcare. Journal for Healthcare Quality, v. 28, n. 2, p. 4, 2006. http://dx.doi.org/10.1111/j.1945-1474.2006.tb00596.x

KOVACH, J.; STRINGFELLOW, P.; TURNER, J.; CHO, B.R., The house of competitiveness: the marriage of agile manufacturing, design for Six Sigma, and Lean manufacturing with quality considerations. Journal of Industrial Technology, v. 21, n. 3, p. 110, 2005.

KRAFCIK, J. F. Triumph of the Lean production system. MIT Sloan Management Review, v. 30, n. 1, p. $41,1988$.

KUMAR SHARMA, R.; GOPAL SHARMA, R. Integrating Six Sigma Culture and TPM Framework to Improve Manufacturing Performance in SMEs. Quality and Reliability Engineering International, v. 30, n. 5, p. 745-765, 2014. http://dx.doi.org/10.1002/qre.1525

KUMAR, M., ANTONY, J.; DOUGLAS, A. Does size matter for Six Sigma implementation? Findings from the survey in UK SMEs. The TQM Journal, v. 21 n. 6, p. 623-635, 2009. http://dx.doi.org/10.1108/17542730910995882

KUMAR, M.; ANTONY, J.; MADU, C.N.; MONTGOMERY, D. C.; PARK, S. H. Common myths of Six Sigma demystified. International Journal of Quality \& Reliability Management, v. 25, n. 8, p. 878-895, 2008. http://dx.doi.org/10.1108/02656710810898658

KUMAR, M.; ANTONY, J.; SINGH, R.K.; TIWARI, M.K.; PERRY, D. Implementing the Lean Sigma framework in an Indian SME: a case study. Production Planning and Control, v. 17, n. 4, p. 407-423, 2006. http://dx.doi.org/10.1080/09537280500483350

KUMAR, M.; ANTONY, J.; TIWARI, M.K. Six Sigma implementation framework for SMEs - a roadmap to manage and sustain the change. International Journal of Production

Research, v. 49, n. 18, p. 5449-5467, 2011.

http://dx.doi.org/10.1080/00207543.2011.563836

LAUREANI, A.; ANTONY, J. Standards for Lean Six Sigma certification. International Journal of Productivity and Performance Management, v. 61, n. 1, p. 110-120, 2012. http://dx.doi.org/10.1108/17410401211188560

LEIPOLD, J.D. Lean Six Sigma efforts near $\$ 2$ billion in savings. Defense AT\&L, v. 36, p. 62-63, 2007.

LUNARDI, M.S; CASTRO, J.M.F.C; MONAT, A.S. Visualização dos resultados do Yahoo em nuvens de texto: uma aplicação construída a partir de web services. Info. Design Revista Brasileira de Design da Informação, v. 5, n. 1, p. 21-35, 2008.

MADER, D.P. Lean Six Sigma's evolution: integrated method uses different deployment models, quality progress. American Society of Quality, p. 40-8, 2008.

MAGUAD, B.A. The modern quality movement: origins, development and trends. Total Quality Management \& Business Excellence, v. 17, n. 2, p. 179-203, 2006.

http://dx.doi.org/10.1080/14783360500450608

Revista Produção Online, Florianópolis, SC, v. 16, n. 2, p. 575-605, abr./jun. 2016. 
MANVILLE, G.; GREATBANKS, R.; KRISHNASAMY, R.; PARKER, D.W. Critical success factors for Lean Six Sigma programmes: a view from middle management. International Journal of Quality \& Reliability Management, v. 29, n. 1, p. 7-20, 2012.

http://dx.doi.org/10.1108/02656711211190846

MARSH, J.; PERERA, T. Lean Six Sigma: Exploring future potencial and challenges. In: ANTONY, J.; KUMAR, M. Lean Six Sigma: Research and Practice. Bookboon, Cap. 2, p. 3545, 2011.

MARTIN, J.W. Lean Six Sigma for Supply Chain Management, the 10-Step Solution Process. The TQM Journal, v. 21 n. 6, p.637-638, 2007.

http://dx.doi.org/10.1108/17542730910995909

MARTINEZ-JURADO, P.J.; MOYANO-FUENTES, J. Key determinants of Lean production adoption: evidence from the aerospace sector. Production Planning \& Control, v. 25, n. 4, p. 332-345, 2012. http://dx.doi.org/10.1080/09537287.2012.692170

MARZAGÃO, D. S. L., LOPES, A. P. V. B. V., GOUVÊA, M. A., \& DE CARVALHO, M. M. Fatores críticos de sucesso na implementação do programa Seis Sigma: uma revisão sistemática das pesquisas quantitativas. Revista Produção Online, v. 14, n. 2, p. 465-498, 2014. http://dx.doi.org/10.14488/1676-1901.v14i2.1348

MAST, J.; DOES, R. J.M.M.; DE KONING, H. Lean Six Sigma for service and healthcare. Journal for Healthcare Quality, v. 28, n. 2, p. 4-11, 2006. http://dx.doi.org/10.1111/j.19451474.2006.tb00596.x

MAST, J.K., B., DOES, R.J., MANDJES, M., BIJL, Y.V.D. Process improvement in healthcare: Overall resource efficiency. Quality and Reliability Engineering International, v. 27 , n. 8 , p. 1095-1106, 2011. http://dx.doi.org/10.1002/qre.1198

MCADAM, R.; ANTONY, J.; KUMAR, M.; HAZLETT, S.A. Absorbing new knowledge in small and medium-sized enterprises: A multiple case analysis of Six Sigma. International Small Business Journal, v. 32, n. 1, p. 81-109, 2014.

http://dx.doi.org/10.1177/0266242611406945

MERCADO, C.I.N. O modelo iTLS tm-integração da Teoria das Restrições, Lean Manufacturing e Seis Sigma: análise da aplicação do iTLS tm na redução do Lead Time em uma cadeia de valor em multinacional no Brasil. 2014. 158f. Dissertação (Mestrado em Engenharia de Produção) - Programa de Pós Graduação em Engenharia de Produção, Universidade Federal do Paraná, Paraná. 2014.

MIKA, G. Six Sigma isn't Lean. Manufacturing Engineering, v. 137, n. 1, 2006.

MORO, G.; DE PÁDUA, F.S.M. Lean Seis Sigma. Interface, v. 5, n. 1, 2008.

NEDERHOF, A.J. Bibliometric monitoring of research performance in the social sciences and the humanities: A review. Scientometrics, USA, v. 66, n. 1, p. 81-100, 2006.

http://dx.doi.org/10.1007/s11192-006-0007-2

NIEMEIJER, G.C.; FLIKWEERT, E.; Trip, A.; Does, R.J.; Ahaus, K.T.; Boot, A.F.; Wendt, K. W. The usefulness of Lean six sigma to the development of a clinical pathway for hip fractures. Journal of Evaluation in Clinical Practice, v. 19, n. 5, p. 909-914, 2013. http://dx.doi.org/10.1111/j.1365-2753.2012.01875.x 
NIEMEIJER, G.C.; TRIP, A.; AHAUS, K.T.; DOES, R.J.; WENDT, K.W. Quality in trauma care: improving the discharge procedure of patients by means of Lean Six Sigma. Journal of Trauma and Acute Care Surgery, v. 69, n. 3, p. 614-619, 2010.

http://dx.doi.org/10.1097/ta.0b013e3181e70f90

OHNO, T. O Sistema Toyota de Produção: além da produção em larga escala. Porto Alegre, 1997.

OLSON, E.G.; BRADY, N. Green Sigma and the Technology of transformation for environmental stewardship. IBM Journal of Research and Development, v. 53, p. 3-1. 2009. http://dx.doi.org/10.1147/jrd.2009.5429016

PEDERSEN, E.R.G.; HUNICHE, M. Determinants of Lean success and failure in the Danish public sector: a negotiated order perspective. International Journal of Public Sector Management, v. 24, n. 5, p. 403-420, 2011. http://dx.doi.org/10.1108/09513551111147141

PEPPER, M.P.J.; SPEDDING, T.A. The evolution of Lean Six Sigma. International Journal of Quality \& Reliability Management. v. 27, n. 2, p. 138-155, 2010.

http://dx.doi.org/10.1108/02656711011014276

PILKINGTON, A.; MEREDITH, J. The evolution of the intellectual structure of operations management - 1980-2006: a citation/co-citation analysis. Journal of Operations Management, v. 27, p. 185-202, 2009. http://dx.doi.org/10.1016/j.jom.2008.08.001

PINHEIRO, T. H.; SCHELLER, A. C.; MIGUEL, P. A. Integração do Seis Sigma com o Lean Production: uma análise por meio de múltiplos casos. Revista Produção Online, v. 13, n. 4, p. 1297-1324, 2013.

PRODANOV, C.C; FREITAS, E.C. Metodologia do Trabalho Científico: Métodos e técnicas da pesquisa e do trabalho acadêmico. 2.ed. Novo Hamburgo: FEEVALE, 2013.

PSYCHOGIOS, A. G.; TSIRONIS, L. K. Towards an integrated framework for Lean Six Sigma application: Lessons from the airline industry. Total Quality Management \& Business Excellence, v. 23, n. 3-4, p. 397-415, 2012.

http://dx.doi.org/10.1080/14783363.2011.637787

REUTTER, J.; WASSENHOVEN, J. Lean/Six Sigma in pharmaceutical industry Theory and practice of successful implementation. Pharmazeutische Industrie, v. 71, 6 ed. P. 10151018, 2009.

ROTH, C.J.; BOLL, D.T.; WALL, L.K.; MERKLE, E.M. Evaluation of MRI acquisition workflow with lean six sigma method: case study of liver and knee examinations. American Journal of Roentgenology, v. 195, n. 2, p. W150-W156, 2010. http://dx.doi.org/10.2214/ajr.09.3678

RUSSELL, R. S.; TAYLOR, B.W. Operations Management, Prentice-Hall, Englewood Cliffs, NJ, 2000.

SALAH, S.; RAHIM, A.; CARRETERO, J.A. The integration of Six Sigma and Lean management. International Journal of Lean Six Sigma, v. 1, n. 3, p. 249-274, 2010. http://dx.doi.org/10.1108/20401461011075035

SCHILDT, H. Sitkis: Software for Bibliometric Data Management and Analysis. Helsinki Institute of Strategy and International Business. v. 6, 2002. 
SCHROEDER, R.G.; LINDERMAN, K.; LIEDTKE, C.; CHOO, A.S. Six Sigma: Definition and underlying theory. Journal of operations Management, v. 26, n. 4, p. 536-554, 2008. http://dx.doi.org/10.1016/i.jom.2007.06.007

SHAH, R.; CHANDRASEKARAN, A.; LINDERMAN, K. In pursuit of implementation patterns: the context of Lean and Six Sigma. International Journal of Production Research, v. 46, n. 23, p. 6679-6699, 2008. http://dx.doi.org/10.1080/00207540802230504

SHANMUGANATHAN, V.K.; HARAN, A.P.; RAGAVENDRAN, S.; GAYATHRI, N. AeroEngine Maintenance Cost Optimization by RCM. Life Science Journal, v. 10, n. 1, 2013. SMALL, H. Paradigms, citations, and maps of science: a personal history. Journal of the American Society for Information Science and Technology, v. 54, n. 5, p. 394-399, 2003. http://dx.doi.org/10.1002/asi.10225

SMITH, B. Lean and Six Sigma - a one-two punch. Quality Progress, v. 36, n.4, p. 37-41, 2003.

SNEE, R. D. Lean Six Sigma - getting better all the time. International Journal of Lean Six Sigma, v. 1, n. 1, p. 9-29, 2010. http://dx.doi.org/10.1108/20401461011033130

SUBRAMANYAM, K. Bibliometric studies of research collaboration: a review. Journal of Information Science, USA, v. 6, n. 1, p. 33, CILIP, 1983.

http://dx.doi.org/10.1177/016555158300600105

SUGIYAMA, H.; SUKOWSKI, L.; SCHMIDT, R. "Japan Quality" in Pharmaceutical Technical Operations Part II: Building a blueprint for better performance in the Japanese market. Pharmazeutische Industrie, v. 73, n. 5, p. 912, 2011.

SUN, J.; WANG, M.H.; HO, Y.S. A historical review and bibliometric analysis of research on estuary pollution. Marine Pollution Bulletin, v. 64, n. 1, p. 13-21, 2012.

http://dx.doi.org/10.1016/j.marpolbul.2011.10.034

TIMANS, W.; ANTONY, J.; AHAUS, K.; VAN SOLINGEN, R. Implementation of Lean Six Sigma in small-and medium-sized manufacturing enterprises in the Netherlands. Journal of the Operational Research Society, v. 63, n. 3, p. 339-353, 2012.

http://dx.doi.org/10.1057/jors.2011.47

VAN LENT, W.A.M.; SANDERS, E.M.; VAN HARTEN, W.H. Exploring improvements in patient logistics in Dutch hospitals with a survey. BMC health services research, v. 12, n. 1, p. 232, 2012. http://dx.doi.org/10.1186/1472-6963-12-232

VIJAYAKUMARAN, V.; RADHAMANI, G.; THANGAIAH, P.R.J. Integrated Framework for Enhancing Software Development Methodologies With Comparative Analysis. J. Comput. Inf. Sci. Eng., v. 14, n. 3, p. 031010, 2014. http://dx.doi.org/10.1115/1.4027889

WANG, F.K.; CHEN, K.S. Applying Lean Six Sigma and TRIZ methodology in banking services. Total Quality Management \& Business Excellence, v. 21, n. 3, p. 301-315, 2010. http://dx.doi.org/10.1080/14783360903553248

WERKEMA, C. Criando a Cultura Lean Seis Sigma. 3. ed, Rio de Janeiro: CAMPUS, 2012.

WERKEMA, C. Lean Seis Sigma: Introdução às ferramentas do Lean manufacturing. 2. ed. Rio de Janeiro: Elsevier, 2011b.

Revista Produção Online, Florianópolis, SC, v. 16, n. 2, p. 575-605, abr.jun. 2016. 
WERKEMA, C. Perguntas e respostas sobre o Lean Seis Sigma. 2. ed. Rio de Janeiro: Elsevier, 2011a.

WOMACK, J.P.; JONES, D.T., Lean Thinking: Banish Waste and Create Wealth in Your Corporation. Journal of the Operational Research Society, v. 48, n. 11, p. 1148-1148, 1997. http://dx.doi.org/10.1038/sj.jors.2600967

WOMACK, J.P.; JONES, D.T.; ROSS, D. The Machine that Changed the World, Rawson Associates, New York, 1990. http://dx.doi.org/10.1002/hfm.4530040310

YEH, H.L.; LIN, C.S.; SU, C.T.; WANG, P.C. Applying Lean six sigma to improve healthcare: An empirical study. African Journal of Business Management, v. 5, n. 31, p. 12356-12370, 2011. http://dx.doi.org/10.5897/ajbm11.1654

ZHANG, Q.; IRFAN, M.; KHATTAK, M.A.O.; ZHU, X.; e HASSAN, M. Lean Six Sigma: a literature review. Interdisciplinary Journal of Contemporary research in business, v. 3 , n. 10, p. 599-605, 2012.

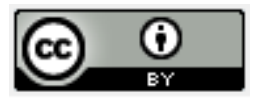

Artigo recebido em 05/05/2015 e aceito para publicação em 01/05/2016

DOI: http://dx.doi.org/ 10.14488/1676-1901.v16i2.2023 